ARTICLE

\title{
Highly selective cesium(I) capture under acidic conditions by a layered sulfide
}

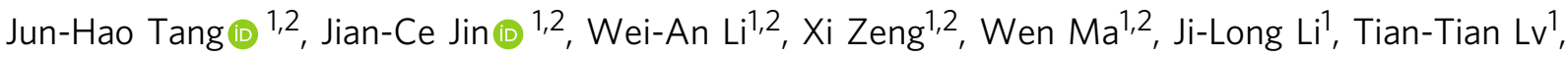 \\ Ying-Chen Peng ${ }^{1,2}$, Mei-Ling Feng (1D ${ }^{1,2,3 凶}$ \& Xiao-Ying Huang (D) ${ }^{1,2}$
}

Radiocesium remediation is desirable for ecological protection, human health and sustainable development of nuclear energy. Effective capture of $\mathrm{Cs}^{+}$from acidic solutions is still challenging, mainly due to the low stability of the adsorbing materials and the competitive adsorption of protons. Herein, the rapid and highly selective capture of $\mathrm{Cs}^{+}$from strongly acidic solutions is achieved by a robust $\mathrm{K}^{+}$-directed layered metal sulfide $\mathrm{K}_{\mathrm{nnSnS}}$ (InSnS-1) that exhibits excellent acid and radiation resistance. InSnS-1 possesses high adsorption capacity for $\mathrm{Cs}^{+}$and can serve as the stationary phase in ion exchange columns to effectively remove $\mathrm{Cs}^{+}$from neutral and acidic solutions. The adsorption of $\mathrm{Cs}^{+}$and $\mathrm{H}_{3} \mathrm{O}^{+}$is monitored by single-crystal structure analysis, and thus the underlying mechanism of selective $\mathrm{Cs}^{+}$ capture from acidic solutions is elucidated at the molecular level.

\footnotetext{
${ }^{1}$ State Key Laboratory of Structural Chemistry, Fujian Institute of Research on the Structure of Matter, Chinese Academy of Sciences, Fuzhou, Fujian 350002 , P. R. China. ${ }^{2}$ University of Chinese Academy of Sciences, Beijing 100049, P. R. China. ${ }^{3}$ Fujian Province Joint Innovation Key Laboratory of Fuel and Materials in Clean Nuclear Energy System, Fujian Institute of Research on the Structure of Matter, Chinese Academy of Sciences, Fuzhou, Fujian 350002, P. R. China.

凶email: fml@fjirsm.ac.cn
} 
W ith the rapid development of nuclear energy, growing concerns about its safety have been raised. ${ }^{137} \mathrm{Cs}$, as the fission product of ${ }^{235} \mathrm{U}$, is one of the main sources of radioactivity in spent fuel $(1230 \mathrm{~g} / \mathrm{ton})^{1} .{ }^{137} \mathrm{Cs}$ with a long halflife $\left(t_{1 / 2} \sim 30.17\right.$ years) can emit $\gamma$-rays ${ }^{1}$. It is highly migratory in the environment, causing cell damage, cancer, and even death in humans ${ }^{2}$. Once radioactive cesium is released into the environment, it will be extremely polluting and cause harm to the entire ecosystem ${ }^{3}$. For example, the Fukushima nuclear accident released a large number of radioactive $\mathrm{Cs}^{+}$ions into the environment, causing total radioactivity levels in some fish to remain above the limit $(100 \mathrm{~Bq} / \mathrm{kg})$ until now ${ }^{4}$. Therefore, the disposal of ${ }^{137} \mathrm{Cs}$ has received much attention due to its potential threat to the environment.

The strongly acidic high-level-liquid-wastes (HLLWs) resulting from the recovery of uranium and plutonium from spent fuel by the PUREX process contain ${ }^{137} \mathrm{Cs}$ in ionic form ${ }^{1,5-7}$. The key for the disposal of HLLWs is the removal of strongly radioactive ions (such as ${ }^{137} \mathrm{Cs}$ ) to reduce their radioactivity level ${ }^{6}$. The separated and purified ${ }^{137} \mathrm{Cs}$ can also be prepared as isotope sources and reused in agriculture and medical fields ${ }^{3}$. However, HLLWs are extremely complex, containing not only $\mathrm{Cs}^{+}$, but also $\mathrm{Sr}^{2+}, \mathrm{Ln}^{3+}$, $\mathrm{Na}^{+}$and so on ${ }^{6,8}$. Such complex components would pose a huge challenge for the selective separation of $\mathrm{Cs}^{+}$from HLLWs. Methods such as solvent extraction, chemical precipitation, and ion exchange/sorption have been used for the enrichment and separation of radiocesium ${ }^{9}$. These methods, however, have some disadvantages in terms of operation, cost, or selectivity, such as the expensive and toxic extractants used in solvent extraction and the great volume of radioactive sludge produced by precipitation ${ }^{10}$. Although ion exchange is considered an ideal method for controlling radioactive contamination due to its simplicity of operation, high efficiency, and lack of secondary contamination ${ }^{11}$, the development of stable and highly selective ion exchangers for the efficient capture of $\mathrm{Cs}^{+}$in acidic solutions still remains a great challenge.

Due to the instability or poor selectivity of materials for $\mathrm{Cs}^{+}$ capture under acidic conditions, most of the current studies are restricted to that under neutral or weak acidic conditions ${ }^{9,11,12}$. In contrast, materials that can effectively remove $\mathrm{Cs}^{+}$ions under extremely acidic condition are still very limited, exemplified mainly by ammonium phosphomolybdate and its complexes or cupric aromatic crown ether-modified silyl compounds ${ }^{13-16}$. In recent years, metal sulfides have been a very promising class of radioactive ion exchangers ${ }^{12,17-20}$ which display excellent removal performance for $\mathrm{Cs}^{+}$. However, the capture of $\mathrm{Cs}^{+}$by metal sulfides under strongly acidic conditions (nitric acid concentrations $>1 \mathrm{~mol} / \mathrm{L}$ ) is challenging, and in particular, the adsorption mechanism has been not clearly identified. Therefore, it is of vital significance to develop acid-tolerant ion exchangers that can selectively capture $\mathrm{Cs}^{+}$from strongly acidic solutions for radioactive liquid waste treatment and to clarify the mechanism of $\mathrm{Cs}^{+}$removal for revealing the structure-function relationship.

Herein, the strategy to improve stability of materials by introducing $\mathrm{Sn}^{4+}$ and $\mathrm{In}^{3+}$ with high valency and large radii into sulfides has been applied. Such an approach leads to a robust $\mathrm{K}^{+}$-directed layered metal sulfide $\mathrm{KInSnS}_{4}$ (denoted as InSnS-1) with excellent acid and irradiation resistances. Specifically, it can maintain its $\left[\mathrm{InSnS}_{4}\right]_{n}{ }^{n-}$ layers even in $1-4 \mathrm{~mol} / \mathrm{L} \mathrm{HNO}_{3}$ solutions. InSnS-1 has high $\mathrm{Cs}^{+}$ion-exchange capacity $\left(q_{\mathrm{m}}{ }^{\mathrm{Cs}}=\right.$ $316.0 \mathrm{mg} / \mathrm{g}$ in neutral solutions; $q_{\mathrm{m}}{ }^{\mathrm{Cs}}=98.6 \mathrm{mg} / \mathrm{g}$ in $1 \mathrm{~mol} / \mathrm{L}$ $\mathrm{HNO}_{3}$ solutions). Under the coexistence of high-concentration competing ions such as $\mathrm{Na}^{+}, \mathrm{Sr}^{2+}$, and $\mathrm{La}^{3+}$, InSnS-1 exhibits high selectivity for $\mathrm{Cs}^{+}$in acidic solutions, which endows InSnS-1 with excellent Cs-Sr or Cs-La separation in the acidic environment. Moreover, ion-exchange columns loaded with InSnS-1 can effectively treat neutral and acidic solutions containing high concentrations of $\mathrm{Cs}^{+}(190.13$ and $84.25 \mathrm{mg} / \mathrm{L}$, respectively) with treatment efficiencies up to 1300 and 650 bed volumes, respectively. The successful determination of the single-crystal structures of InSnS-1 and its three ion-exchange products help visualize the ion exchange between $\mathrm{Cs}^{+}$or hydrated protons $\left(\mathrm{H}_{3} \mathrm{O}^{+}\right)$and interlayered $\mathrm{K}^{+}$ions of InSnS-1. This is a systematic study of the selective $\mathrm{Cs}^{+}$capture under strongly acidic condition with an emphasis on revealing the capture mechanism at the molecular level.

\section{Results}

Synthesis. Among the reported metal sulfide ion exchangers, $\mathrm{K}_{2 x} \mathrm{Mn}_{x} \mathrm{Sn}_{3-x} \mathrm{~S}_{6} \quad\left(x=0.5-0.95\right.$, KMS-1) and $\mathrm{KInSn}_{2} \mathrm{~S}_{6}$ (KMS-5) have shown excellent acid resistance (retaining the parent structure at $\mathrm{pH}<1)^{8,17,21}$. A common feature of both compounds is the high coordination number of metal ions in the framework (i.e., metal ions are coordinated with six S atoms to form octahedral geometries), which is the highest among the reported metal sulfide ion exchangers $8,17,22$. The high coordination of metal ions may be beneficial to the structural stability of metal sulfides. In addition, it has been shown that the introduction of high-valency metal ions in the framework helps to resist the exchange of competing protons $^{8}$. Therefore, we used the strategy of introducing highvalency, large-radius metal ions to synthesize metal sulfides with highly coordinated metal ions aiming to improve the acid stability of sulfide ion exchangers and their ability to selectively capture target ions. Thus, a robust $\mathrm{K}^{+}$-directed layered metal sulfide InSnS-1 has been synthesized by a simple solid-phase method according to the following reaction formula (Eq. (1)):

$$
\mathrm{KInS}_{2}+\mathrm{Sn}+2 \mathrm{~S} \stackrel{750^{\circ} \mathrm{C}, 4 \text { days }}{\longrightarrow} \mathrm{KInSnS}_{4}
$$

Although $\mathrm{KInSnS}_{4}$ with the same stoichiometric ratio has been reported, the previous synthesis methods yielded mixed phase of $\mathrm{KInSnS}_{4}$ with two distinct structures $\left(\alpha-\mathrm{KInSnS}_{4}\right.$ and $\beta$ $\left.\mathrm{KInSnS}_{4}\right)^{23}$. Moreover, the previous synthesis methods reported are operationally complex, requiring the use of $\mathrm{CS}_{2}$ vapor stream or $\mathrm{K}_{2} \mathrm{CO}_{3}$. Notably, when $\mathrm{K}_{2} \mathrm{CO}_{3}$ is used, the reaction mixture usually needs to be heated to a specific temperature to release carbon dioxide firstly before sealing the quartz tube. By contrast, $\mathrm{KInS}_{2}$ as a precursor was utilized here, which allows the synthesis of single-phase $\mathrm{KInSnS}_{4}$ (InSnS-1) on a large scale easily. Moreover, though the structure of InSnS-1 is similar with $\alpha$-KInSnS 4 , InSnS- 1 shows different $\mathrm{K}^{+}$positions. The detail can be found in the following crystal structures part.

Crystal structures and insight into the $\mathrm{Cs}^{+}$removal mechanism under neutral and acidic conditions. The reported $\alpha$-KInSnS 4 and $\beta$-KInSnS 4 both present two-dimensional (2D) anionic layer of $\left[\mathrm{InSnS}_{4}\right]_{n}{ }^{n-}$ formed by $\left[(\mathrm{In} / \mathrm{Sn}) \mathrm{S}_{6}\right]$ octahedra interconnected via edge sharing ${ }^{23}$. The difference is that in $\alpha$-KInSnS 4 , the $\mathrm{S}$ atoms in the $\left[(\mathrm{In} / \mathrm{Sn}) \mathrm{S}_{6}\right]$ octahedron are disordered with half-occupancy resulting in two alternative orientations for $\left[\mathrm{InSnS}_{4}\right]_{n}{ }^{n-}$ layers (Supplementary Fig. 3) ${ }^{23}$. Accordingly, the interlayer disordered $\mathrm{K}^{+}$ions are hexa-coordinated with $\mathrm{S}$ atoms to form $\mathrm{KS}_{6}$ with both triangular antiprismatic and prismatic orientations in $\alpha-\mathrm{KInSnS}_{4}$, while only triangular antiprismatic $\mathrm{KS}_{6}$ are formed in $\beta$ - $\mathrm{KInSnS}_{4}{ }^{23}$. Although it seems that InSnS- 1 has similar structure as $\alpha$-KInSnS (Supplementary Fig. 3), structural refinements of InSnS-1 show that the $\mathrm{K}^{+}$ions reside in two different sites of $\mathrm{K} 1(1 b)$ and $\mathrm{K} 1 \mathrm{~B}$ (2d), rather than only one site (1b) in $\alpha$-KInSnS 4 (Supplementary Fig. $4 a, b)$.

The ion-exchange properties of $\alpha-\mathrm{KInSnS}_{4}$ and $\beta$ - $\mathrm{KInSnS}_{4}$, especially for the selective capture of $\mathrm{Cs}^{+}$under strongly acidic condition have not been systematically investigated. In order to 


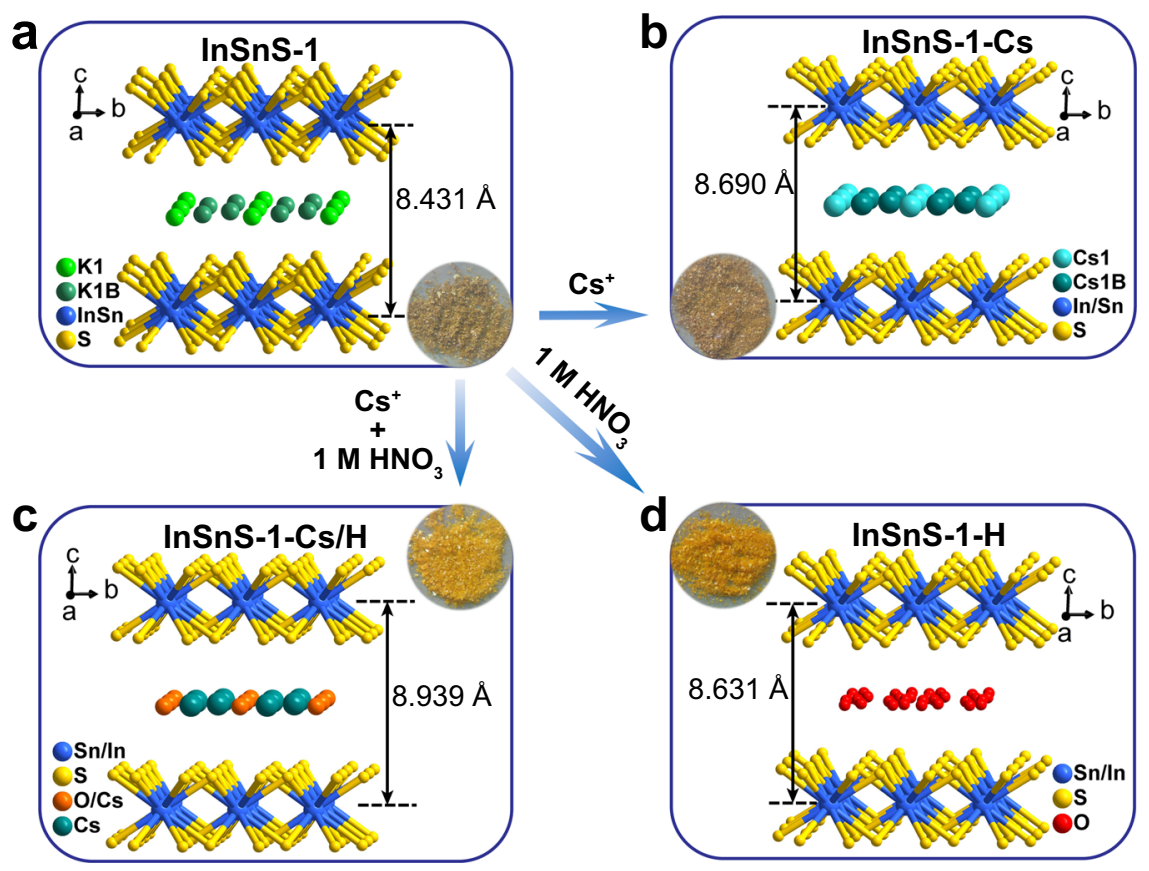

Fig. 1 Crystal structures diagrams before and after ion exchange. View of the crystal structures of $\mathbf{a} \ln S n S-1, \mathbf{b} \operatorname{lnSnS}-1-\mathrm{Cs}, \mathbf{c} \operatorname{lnSnS}-1-\mathrm{Cs} / \mathrm{H}$, and $\mathbf{d} \ln S n S-1-$ $\mathrm{H}$ along $a$ axis.

investigate the capture mechanism of $\mathrm{Cs}^{+}$under neutral and acidic conditions, the single-crystal structures of ion-exchange products (InSnS-1-Cs, InSnS-1-Cs/H, InSnS-1-H) were analyzed and compared with that of the pristine InSnS-1. This allows us to visualize the mechanism of selective $\mathrm{Cs}^{+}$capture by InSnS-1 and effects of protons on the process of $\mathrm{Cs}^{+}$capture. Combining single-crystal structure analysis and EDS results, the ion-exchange reaction can be represented by the following equations (Eqs. (2)-(4)):

$$
\begin{gathered}
\mathrm{KInSnS}_{4}+\mathrm{Cs}^{+} \rightarrow \mathrm{CsInSnS}_{4}(\mathrm{InSnS}-1-\mathrm{Cs})+\mathrm{K}^{+} \\
\mathrm{KInSnS}_{4}+\frac{1}{3} \mathrm{Cs}^{+}+\frac{2}{3} \mathrm{H}_{3} \mathrm{O}^{+} \rightarrow \mathrm{Cs}_{\frac{1}{3}}\left(\mathrm{H}_{3} \mathrm{O}\right)_{\frac{2}{3}} \mathrm{InSnS}_{4}(\mathrm{InSnS}-1-\mathrm{Cs} / \mathrm{H})+\mathrm{K}^{+}
\end{gathered}
$$

$$
\mathrm{KInSnS}_{4}+\mathrm{H}_{3} \mathrm{O}^{+}+\mathrm{H}_{2} \mathrm{O} \rightarrow\left(\mathrm{H}_{3} \mathrm{O}\right) \mathrm{InSnS}_{4} \cdot \mathrm{H}_{2} \mathrm{O}(\mathrm{InSnS}-1-H)+\mathrm{K}^{+}
$$

Detailed structural information of compounds is shown in Supplementary Tables 1-6. Compared with InSnS-1, both InSnS1-Cs and InSnS-1-Cs/H exhibit an increase in the interlayer spacing (from $8.431 \AA$ to $8.690 \AA$ and $8.939 \AA$, respectively; Fig. $1 \mathrm{a}-\mathrm{c})$, which is attributed to the substitution of $\mathrm{K}^{+}(138 \mathrm{pm})$ by $\mathrm{Cs}^{+}$with larger radius $(170 \mathrm{pm})^{24}$. Although the radius of $\mathrm{H}_{3} \mathrm{O}^{+}(112 \mathrm{pm})^{24}$ is smaller than that of $\mathrm{K}^{+}$, the interlayer spacing of InSnS-1-H still increases to $8.631 \AA$ because of the entry of one lattice water molecule per formula. These results indicate that the interlayer spacing of InSnS-1 is tunable upon ion exchange and its layer structure shows flexibility even under acidic conditions, which contributes to the effective capture of $\mathrm{Cs}^{+}$.

It is noteworthy that each $\mathrm{Cs}^{+}$ion is coordinated by six $\mathrm{S}$ atoms to form $\mathrm{CsS}_{6}$ with triangular antiprismatic and prismatic geometries in both InSnS-1-Cs and InSnS-1-Cs/H with Cs-S distances of $3.606 \AA$ and $3.675 \AA$, respectively (Supplementary Fig. 5), which indicate strong interactions between $\mathrm{S}^{2-}$ and $\mathrm{Cs}^{+}$. Based on Pearson's Hard-Soft-Acid-Base (HSAB) theory ${ }^{25}, \mathrm{~K}^{+}$is a hard acid whereas $\mathrm{Cs}^{+}$is relatively softer. Thus, the soft basic
$\mathrm{S}^{2-}$ from $\left[\mathrm{InSnS}_{4}\right]_{n}{ }^{n-}$ layers has a stronger affinity for relatively soft acidic $\mathrm{Cs}^{+}$than $\mathrm{K}^{+}$. Therefore, the flexible framework and the adjustable layer spacing of InSnS-1 as well as the strong interaction of $\mathrm{Cs}^{+}$with $\mathrm{S}^{2-}$ play important roles for the rapid and highly selective capture of $\mathrm{Cs}^{+}$.

In addition, $\mathrm{K}^{+}$ions can be completely exchanged by $\mathrm{H}_{3} \mathrm{O}^{+}$ ions under acidic conditions without $\mathrm{Cs}^{+}$ions. $\mathrm{H}_{3} \mathrm{O}^{+}$ions or water molecules become more disordered between the layers in InSnS-1-H (Fig. 1d). Although there have been studies on the capture of $\mathrm{Cs}^{+}$, the clear structural revelation is still scarce $26-29$. Especially, the microstructural illumination for the selective $\mathrm{Cs}^{+}$ capture under acidic conditions has not been reported. The current deep insight into the structural analyses facilitates the understanding of the mechanism of selective $\mathrm{Cs}^{+}$capture by ion exchange and provides a reference for the design and synthesis of novel ion exchangers with the high selectivity for target radionuclides.

To further investigate the relationship between structures and properties of materials, a number of $\mathrm{K}^{+}$-directed layered or threedimensional (3D) microporous sulfides including 3D$\mathrm{K}_{4} \mathrm{Cu}_{8} \mathrm{Ge}_{3} \mathrm{~S}_{12}{ }^{30}, 2 \mathrm{D}-\mathrm{KCu}_{2} \mathrm{SbS}_{3}{ }^{31}, 2 \mathrm{D}-\mathrm{KYS}_{2}{ }^{32}$. have been synthesized. It is a pity that our preliminary batch absorption experiments show that they have no $\mathrm{Cs}^{+}$ion-exchange properties. To comparatively analyze the structure-function relationship, the reported structures including $2 \mathrm{D}-\mathrm{KMS}-1^{17,22}, 2 \mathrm{D}-\mathrm{KMS}$ $2^{18}, 2 \mathrm{D}-\mathrm{KTS}-3^{19}$. and their ion-exchange properties have been also summarized. The shortest distances from $\mathrm{K}^{+}$to anionic frameworks (noted as $D_{\min }{ }^{\mathrm{K}-\mathrm{S}}$ ) and the coordination numbers of $\mathrm{K}^{+}$have been summarized (Supplementary Table 7).

In the case of $2 \mathrm{D}$ layered sulfides, $2 \mathrm{D}-\mathrm{KYS}_{2}$ features an anionic layer of $\left[\mathrm{YS}_{2}\right]_{n}{ }^{n-}$ built up by edge-sharing $\left[\mathrm{YS}_{6}\right]$ octahedra ${ }^{32}$, which is similar to KMS ion exchangers ${ }^{8,17,18}$. However, $2 \mathrm{D}-\mathrm{KYS}_{2}$ does not have ion-exchange properties for $\mathrm{Rb}^{+}, \mathrm{Cs}^{+}$, and $\mathrm{Sr}^{2+}$, even though $2 \mathrm{D}-\mathrm{RbYS}_{2}{ }^{32}$ with the same layer structure as $\mathrm{KYS}_{2}$ has been reported. It is found that $D_{\min } \mathrm{K}-\mathrm{S}$ in $2 \mathrm{D}-\mathrm{KYS}_{2}(3.174 \AA)$ is much shorter than those in 2D-KMS-1 (3.353 $\AA$ ), 2D-KMS-2 (3.494 $\AA$ ), and 2D-KMS-5 (3.439 $\AA$ ). $2 \mathrm{D}-\beta-\mathrm{K}_{2} \mathrm{CdSn}_{2} \mathrm{~S}_{6}{ }^{33}$ with short $D_{\min }{ }^{\mathrm{K}-\mathrm{S}}(3.157 \AA)$ also cannot undergo ion-exchange 
reactions. Thus, the strong attraction between $\mathrm{S}^{2-}$ of anionic layers and $\mathrm{K}^{+}$makes it difficult for $\mathrm{K}^{+}$to escape. In the case of $3 \mathrm{D}$ microporous sulfides, $3 \mathrm{D}-\mathrm{K}_{3} \mathrm{Ga}_{3} \mathrm{Ge}_{7} \mathrm{~S}_{20}$ has a large $D_{\min } \mathrm{K}-\mathrm{S}$ (3.281 $\AA$ ) but cannot accommodate other ions such as $\mathrm{Cs}^{+}$due to small pore size excluding $\mathrm{K}^{+}(3.7 \AA \times 19.4 \AA)^{34}$. Conversely, 3D$\mathrm{K}_{6} \mathrm{Sn}\left[\mathrm{Zn}_{4} \mathrm{Sn}_{4} \mathrm{~S}_{17}\right]^{35}$ has three different cavities, namely K1, K2, K3 cavities. The $\mathrm{K}^{+}$ions (K3: 4 coordination, $D_{\min }{ }^{\mathrm{K}-\mathrm{S}}=3.253 \AA$ ) in K3 cavity (diameter: $\sim 4.1 \AA$ ) can be easily exchanged by $\mathrm{Cs}^{+}$with strong selectivity. The $\mathrm{K}^{+}$ions in the smaller $\mathrm{K} 1$ and $\mathrm{K} 2$ cavities ( $3.0 \AA$; K1: 8 coordination, $D_{\min }{ }^{\mathrm{K}-\mathrm{S}}=3.446 \AA$; $\mathrm{K} 2: 6$ coordination, $D_{\min }{ }^{\mathrm{K}-\mathrm{S}}=3.144 \AA$ ) , however, cannot be exchanged by $\mathrm{Cs}^{+}$ due to the limitation of the pore size.

Based on these facts, it can be inferred that $D_{\min }{ }^{\mathrm{K}-\mathrm{S}}$ is one of the main key factors in determining whether ion exchange occurs for layered sulfides. The smaller the value of $D_{\min }{ }^{\mathrm{K}-\mathrm{S}}$ is, the more attractive the anionic sulfide framework is for $\mathrm{K}^{+}$, and the less likely ion exchange will occur. Based on the currently available data, we can tentatively assume that ion exchange can be realized when $D_{\min }{ }^{K-S}$ is longer than $3.30 \AA$, and otherwise ion-exchange reaction difficulty occurs for layered sulfides. $D_{\min }{ }^{\mathrm{K}-\mathrm{S}}$ of $2 \mathrm{D}$ InSnS- 1 is $3.503 \AA$ here, and thus the current compound exhibits excellent ion-exchange property. However, for $3 \mathrm{D}$ microporous compounds, the pore size and the coordination number of $\mathrm{K}^{+}$are also necessary factors in addition to the $D_{\min }{ }^{\mathrm{K}-\mathrm{S}}$. If necessary, elevated reaction conditions will favor the promotion of ionexchange reactions ${ }^{35}$. Of course, the universal conclusion remains to be analyzed in more depth with more examples.

Characterizations of ion-exchange products. Single-crystal Xray diffraction directly confirms that InSnS-1-Cs, InSnS-1-Cs/H, and InSnS-1-H can be obtained by ion exchange of InSnS-1 under different conditions. The successful ion exchange of $\mathrm{K}^{+}$by $\mathrm{Cs}^{+}$or $\mathrm{H}_{3} \mathrm{O}^{+}$can be further corroborated by EDS, XPS, ICP. The X-ray powder diffraction patterns of InSnS-1 and its ion-exchange products were in high agreement with the corresponding singlecrystal simulated ones (Supplementary Fig. 7). The elemental distribution mapping and EDS analysis results of ion-exchange products show that $\mathrm{Cs}^{+}$ions are evenly distributed in the samples (Supplementary Figs. 8 and 9). As seen in the XPS spectra (Supplementary Fig. 10), two peaks of K $2 p$ at $292.1 \mathrm{eV}\left(\mathrm{K} 2 p_{3 / 2}\right)$ and $294.8 \mathrm{eV}\left(\mathrm{K} 2 p_{1 / 2}\right)$ disappeared after $\mathrm{Cs}^{+}$or $\mathrm{H}_{3} \mathrm{O}^{+}$ion exchange, which confirms that $\mathrm{K}^{+}$ions were completely exchanged. Conversely, the appearance of Cs $3 d_{5 / 2}$ and Cs $3 d_{3 / 2}$ peaks at $723.3 \mathrm{eV}$ and $737.2 \mathrm{eV}$ was observed in the XPS spectra of InSnS-1-Cs and InSnS-1-Cs/ $\mathrm{H}^{36}$.

Compared to InSnS-1, InSnS-1-Cs has a significantly darker yellow color, while InSnS-1-Cs/H and InSnS-1-H display lighter yellow colors (Fig. 1), which correlates with the redshift and blueshift of their optical absorption edges, respectively. Compared to InSnS-1 $(2.211 \mathrm{eV})$, the optical absorption edge of InSnS-1-Cs is slightly red-shifted to $2.147 \mathrm{eV}$, while InSnS-1-Cs/H and InSnS$1-\mathrm{H}$ are blue-shifted to 2.255 and $2.220 \mathrm{eV}$, respectively (Supplementary Fig. 11). TG analysis (Supplementary Fig. 12) shows that InSnS-1 has good thermal stability. In addition, it can be seen that the exchanged products have obvious delamination compared with the pristine from the SEM images (Supplementary Figs. 13 and 14).

Acid stability studies. A scavenger for $\mathrm{Cs}^{+}$should be acid-stable as HLLWs are typically highly acidic ${ }^{6}$. The InSnS- 1 crystals retained the crystallinity and the layered network after being immersed in highly concentrated $(0.1-4 \mathrm{~mol} / \mathrm{L})$ acidic solutions for $10 \mathrm{~h}$ (Fig. 2a, b). The leaching rates of $\mathrm{In}^{3+}$ and $\mathrm{Sn}^{4+}$ in solution were less than $2.79 \%$ and $0.06 \%$, respectively, which further confirms the high acid resistance of InSnS-1 (Fig. 2c). As

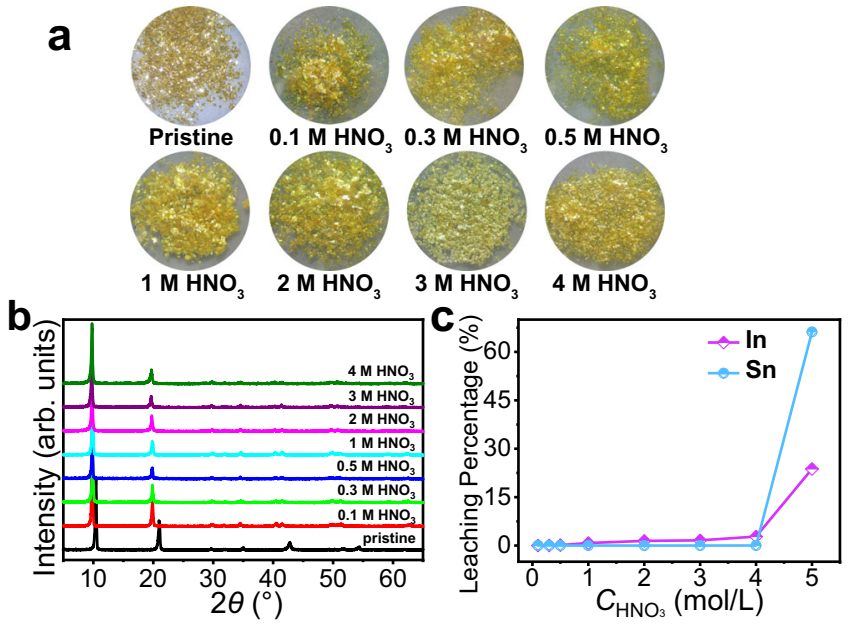

Fig. 2 Acid stability studies of InSnS-1. a Photographs of pristine InSnS-1 and its crystals after immersion in different concentrations of nitric acid solutions. b X-ray powder diffraction spectra of InSnS-1 and its corresponding samples after soaking in different concentrations of nitric acid solutions. c In/Sn leaching percentage curves of InSnS-1. Detailed experimental data can be found in Supplementary Table 8.

the acidity increased further to $5 \mathrm{~mol} / \mathrm{L} \mathrm{HNO}_{3}$, the substance began to break down.

Kinetic studies of $\mathrm{Cs}^{+}$ion removal. It is essential that the ion exchanger is able to capture the target ions quickly. Therefore, kinetic experiments for the $\mathrm{Cs}^{+}$capture by InSnS- 1 in neutral and strongly acidic solutions were carried out. In neutral solution, the removal rate $R(\%)$ of $\mathrm{Cs}^{+}$by $\mathrm{InSnS}-1$ rapidly reached over $90 \%$ within $5 \mathrm{~min}$ (Fig. 3a). In $1 \mathrm{~mol} / \mathrm{L} \mathrm{HNO}_{3}$ solution, $R^{\mathrm{Cs}}$ also rapidly reached over $80 \%$ within $20 \mathrm{~min}$ (Fig. 3b). Such a fast and efficient removal of $\mathrm{Cs}^{+}$under acidic conditions is rarely reported because ion-exchange competition with protons is a severe issue $^{8,20}$. Compared to the pseudo-first-order kinetics model ${ }^{37}$, the kinetic data of $\mathrm{Cs}^{+}$capture by $\mathrm{InSnS}-1$ in neutral and $1 \mathrm{~mol} / \mathrm{L}$ $\mathrm{HNO}_{3}$ solutions were better fitted with the pseudo-second-order kinetics model ${ }^{37}$ with high correlation coefficients $R^{2}(>0.9999)$ (Supplementary Fig. 15), which proves that the adsorption process is chemical sorption ${ }^{38}$.

$\mathrm{Cs}^{+}$ion adsorption isotherm studies. The exchange capacities of InSnS-1 for $\mathrm{Cs}^{+}$in neutral and $1 \mathrm{~mol} / \mathrm{L} \mathrm{HNO}_{3}$ solutions at room temperature (RT) have been measured by static batch experiments. The ion-exchange capacity can be determined by fitting the equilibrium data with the Langmuir and the Langmuir-Freundlich isotherm models ${ }^{39}$. The isotherm curves (Fig. 3c, d) were better fitted with the Langmuir-Freundlich isotherm model, with the correlation coefficients $\left(R^{2}\right)$ of 0.99 and 0.98 in neutral and $1 \mathrm{~mol} / \mathrm{L} \mathrm{HNO}_{3}$ solutions, respectively. The maximum exchange capacity $\left(q_{\mathrm{m}}{ }^{\mathrm{Cs}}\right)$ of InSnS- 1 for $\mathrm{Cs}^{+}$reached $316 \mathrm{mg} / \mathrm{g}$ in neutral solutions, which is higher than that of many common $\mathrm{Cs}^{+}$adsorbents ${ }^{9}$, including bentonite (Turkish samples: $300.35 \mathrm{mg} / \mathrm{g})^{40}$, zeolite (Turkish samples: $89.18 \mathrm{mg} / \mathrm{g}$ ) ${ }^{40}$, ferricyanide (Prussian blue granules: $241 \mathrm{mg} / \mathrm{g}$ ) ${ }^{41}$, carbon-based materials (GO: $76.9 \mathrm{mg} / \mathrm{g}$ ) ${ }^{42}$, metal sulfides (KMS-1 $1^{17}: 226 \mathrm{mg} / \mathrm{g}$, KTS- $3^{19}: 280 \mathrm{mg} / \mathrm{g}$ ) and is also higher than that of the commercially available AMP-PAN ${ }^{43}(81 \mathrm{mg} / \mathrm{g})$. It is noteworthy that InSnS-1 can still hold an exchange capacity for $\mathrm{Cs}^{+}$of $98.6 \mathrm{mg} / \mathrm{g}$ in strongly acidic solutions $\left(1 \mathrm{~mol} / \mathrm{L} \mathrm{HNO}_{3}\right)$, which is even higher than that of KMS-1 at $\mathrm{pH}=0.8(\sim 90 \mathrm{mg} / \mathrm{g})^{17}$. Noteworthy is that 

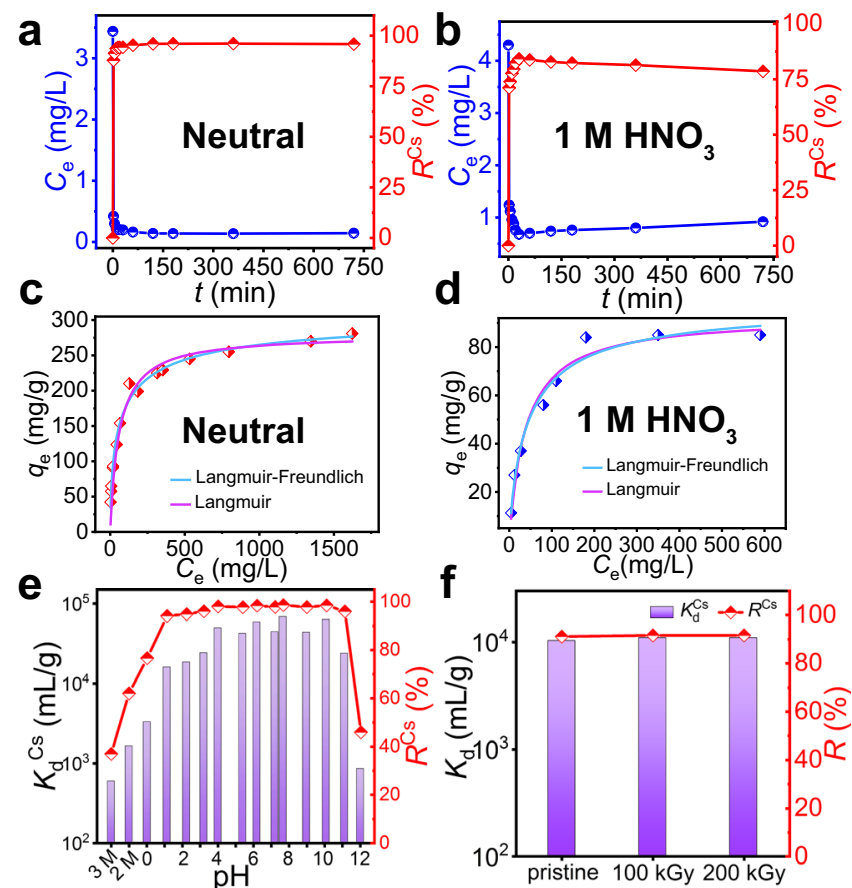

Fig. 3 Adsorption kinetics, adsorption isotherms, pH-dependent studies, and irradiation stability studies of InSnS-1. Kinetics of $\mathrm{Cs}^{+}$removal by InSnS-1 under a neutral and $\mathbf{b} 1 \mathrm{~mol} / \mathrm{L} \mathrm{HNO}_{3}$ solutions plotted as $\mathrm{Cs}^{+}$ concentration and the removal rate of $\mathrm{Cs}^{+}$vs the time $t(\mathrm{~min})$, respectively. Equilibrium data for $\mathrm{Cs}^{+}$ion exchange by $\operatorname{lnSnS}-1$ in $\mathbf{c}$ neutral and $\mathbf{d} 1 \mathrm{~mol} / \mathrm{L}$ $\mathrm{HNO}_{3}$ solutions. $K_{\mathrm{d}} \mathrm{Cs}^{\mathrm{S}}$ and $R^{\mathrm{Cs}}$ values of $\mathrm{InSnS}-1$ at various initial $\mathrm{pH}$ values ( $2 \mathrm{M}=2 \mathrm{~mol} / \mathrm{L} \mathrm{HNO}_{3}, 3 \mathrm{M}=3 \mathrm{~mol} / \mathrm{L} \mathrm{HNO}_{3}$, purple bar: $K_{\mathrm{d}} \mathrm{Cs}$, red dotted line: $R^{\mathrm{Cs}}$ ). $\mathbf{f} K_{\mathrm{d}}^{\mathrm{Cs}}$ and $R^{\mathrm{Cs}}$ values of the InSnS-1 samples before and after irradiation. Detailed experimental data can be found in Supplementary Tables 9-14.

the adsorption capacity of sulfide materials for $\mathrm{Cs}^{+}$under such strongly acidic condition has not been found before.

pH-dependent experiments. In general, the $\mathrm{pH}$ value of solution has an effect on the adsorption/ion exchange ${ }^{20,44,45}$. The majority of reported materials are unstable under strongly acidic conditions or their ion-exchange properties are significantly reduced due to the effects of protonation ${ }^{8,20}$. Some previously reported good-performance $\mathrm{Cs}^{+}$ion-exchange metal sulfides have shown a significant decrease in their ion-exchange performance when the concentration of $\mathrm{HNO}_{3}$ just approaches $1 \mathrm{~mol} / \mathrm{L}^{18,19,46}$. For example, KMS- $2^{18}$, KTS- $3^{19}$, and FJSM-SnS ${ }^{46}$ have reduced $K_{\mathrm{d}}$ Cs of around $10^{3} \mathrm{~mL} / \mathrm{g}$ at $\mathrm{pH}=3,2$, and 0.7 , respectively. Therefore, $\mathrm{pH}$-dependent experiments for the $\mathrm{Cs}^{+}$removal by InSnS-1 were carried out. The distribution coefficient $\left(K_{\mathrm{d}}\right)$ was calculated to describe the affinity of the material for the target ions.

InSnS-1 maintained excellent removal performance for $\mathrm{Cs}^{+}$over a wide range of $\mathrm{pH}$ values from 1.14 to 11.14 , with $R^{\mathrm{Cs}}>94 \%$ and $K_{\mathrm{d}}{ }^{\mathrm{Cs}}$ values all above $10^{4} \mathrm{~mL} / \mathrm{g}$ (Fig. $3 \mathrm{e}$ ). The $K_{\mathrm{d}}{ }^{\mathrm{Cs}}$ value was still $3.3 \times 10^{3} \mathrm{~mL} / \mathrm{g} \quad\left(R^{\mathrm{Cs}}=76.6 \%\right)$ at $\mathrm{pH}=0.02$ and it reached $1.6 \times 10^{3} \mathrm{~mL} / \mathrm{g}\left(R^{\mathrm{Cs}}=62.1 \%\right)$ even in $2 \mathrm{~mol} / \mathrm{L} \mathrm{HNO}_{3}$ solution. These indicate that in strongly acidic solutions InSnS-1 still has the ability to remove $\mathrm{Cs}^{+}$. It is very rare that such high efficiency can be retained under such strongly acidic solutions. Impressive, InSnS-1 was able to maintain the framework stability during ion exchange over a wide $\mathrm{pH}$ range $(\mathrm{pH}=0.02-12.02)$ and in strongly acidic solutions ( 2 and $3 \mathrm{~mol} / \mathrm{L}_{\mathrm{HNO}}$ ), which was confirmed by PXRD (Supplementary Fig. 16). Conversely, excellent sulfide-based ion-exchange materials such as KMS- $2^{18}$, KTS- ${ }^{19}$, FJSM-GAS- $1^{47}$,
FJSM-GAS- ${ }^{47}$, InS- $1^{48}$, InS- $2^{49}$, and K@GaSnS- $1^{50}$ have the disrupted frameworks at $\mathrm{pH}=2-3$. Although KMS- $1^{22}$ and FJSM$\mathrm{SnS}^{46}$ are more acid-resistant, their frameworks could only remain stable at $\mathrm{pH}$ of around 0.7 . When the acidity is further enhanced, KMS-1 retains its lamellar structure but the composition of the layer structure changes ${ }^{21}$. In a word, metal sulfides with high stability and excellent $\mathrm{Cs}^{+}$ion-exchange properties under strongly acidic conditions are rare, while the excellent performance of InSnS-1 certainly highlights the feasibility of metal sulfides for $\mathrm{Cs}^{+}$ removal in acidic waste streams.

Irradiation stability studies. Irradiation stability is one of the necessary properties for radioactive ion scavengers. Therefore, the $\mathrm{Cs}^{+}$ion-exchange capacities of InSnS-1 samples after $100 \mathrm{kGy}$ and $200 \mathrm{kGy} \quad \gamma$-irradiation were investigated. The results demonstrate that InSnS-1 has excellent irradiation stability, maintaining stable structure and ion-exchange properties $\left(R^{\mathrm{Cs}}>91 \%, K_{\mathrm{d}}{ }^{\mathrm{Cs}}>10^{4} \mathrm{~mL} / \mathrm{g}\right)$ after intense irradiation (Fig. 3f, Supplementary Fig. 17).

Competitive experiments in the presence of interfering ions. The selective extraction of $\mathrm{Cs}^{+}$from HLLWs containing high concentrations of $\mathrm{Na}^{+}$has been a major challenge because $\mathrm{Na}^{+}$ and $\mathrm{Cs}^{+}$have similar hydration radii $\left(219 \mathrm{pm}\right.$ for $\mathrm{Na}^{+}$and $218 \mathrm{pm}$ for $\left.\mathrm{Cs}^{+}\right)^{8,24}$. Therefore, the performances of InSnS-1 capturing $\mathrm{Cs}^{+}$in neutral and acidic solutions with different $\mathrm{Na} / \mathrm{Cs}$ molar ratios were investigated in detail. In neutral solutions, $K_{\mathrm{d}} \mathrm{Cs}$ could still amount to $10^{3} \mathrm{~mL} / \mathrm{g}$ when the $\mathrm{Na} / \mathrm{Cs}$ molar ratio was $380\left(R^{\mathrm{Cs}}=50.37 \%\right.$, Fig. $\left.4 \mathrm{a}\right)$. In $1 \mathrm{~mol} / \mathrm{L} \mathrm{HNO}_{3}$ solutions, $K_{\mathrm{d}} \mathrm{Cs}$ could still reach $2.16 \times 10^{3} \mathrm{~mL} / \mathrm{g}\left(R^{\mathrm{Cs}}=68.35 \%\right)$ even when the $\mathrm{Na}$ /Cs molar ratio was $1.92 \times 10^{3}$ (Fig. $4 \mathrm{~b}$ ). Importantly, $R^{\mathrm{Cs}}$ and $K_{\mathrm{d}} \mathrm{Cs}$ of InSnS-1 in $1 \mathrm{~mol} / \mathrm{L} \mathrm{HNO}_{3}$ solutions were higher than those in neutral solutions when the $\mathrm{Na} / \mathrm{Cs}$ molar ratios were in the range from 190 to $3.07 \times 10^{3}$, and the highest values of $K_{\mathrm{d}}{ }^{\mathrm{Cs}}$ and $R^{\mathrm{Cs}}$ were $4.0 \times 10^{3} \mathrm{~mL} / \mathrm{g}$ and $79.71 \%$, respectively (Supplementary Fig. 18). Even in $3 \mathrm{~mol} / \mathrm{L} \mathrm{HNO}_{3}$ solutions with $\mathrm{Na} / \mathrm{Cs}$ molar ratios of about $2.9 \times 10^{3}$ and $5.8 \times 10^{3}, R^{\mathrm{Cs}}$ could still reach $37.11 \%$ and $31.06 \%$, respectively, which were higher than $R^{\mathrm{Cs}}$ values in neutral or $1 \mathrm{~mol} / \mathrm{L}_{\mathrm{HNO}_{3}}$ solutions under the same conditions (Fig. 4c, Supplementary Fig. 18). The separation factor $S F_{\mathrm{Cs} / \mathrm{Na}}$ of InSnS-1 in $1 \mathrm{~mol} / \mathrm{L} \mathrm{HNO}_{3}$ solutions exceeded 100 when the $\mathrm{Na} / \mathrm{Cs}$ molar ratios were 191,387 , and $983\left(S F_{\mathrm{Cs} / \mathrm{Na}}\right.$ were $172.3,109.6$, and 166.2 , respectively). $S F$ is related to the selectivity of the material which is used to measure whether the two ions can be well separated $^{18}$. Excellent selectivity can be considered when the SF value is higher than $100^{18}$. Such excellent selectivity of InSnS-1 for $\mathrm{Cs}^{+}$is attributed to that $\mathrm{Na}^{+}$is hard acid, while $\mathrm{Cs}^{+}$is softer acid compared to $\mathrm{Na}^{+}$. According to HSAB theory ${ }^{25}$, the soft base $\mathrm{S}^{2-}$ has a stronger affinity for $\mathrm{Cs}^{+}$than $\mathrm{Na}^{+}$.

The effect of some other ions in HLLWs (represented by $\mathrm{Sr}^{2+}$ and $\mathrm{La}^{3+}$ ) on the selective capture of $\mathrm{Cs}^{+}$cannot be neglected; thus, extra experiments were performed ${ }^{8}$. In the individual competing ion system, the influence of solution acidity and competing ion concentrations on the performance of InSnS-1 in removing $\mathrm{Cs}^{+}$is similar. Under neutral conditions, when the concentrations of $\mathrm{Cs}^{+}$and competing $\mathrm{Sr}^{2+}$ or $\mathrm{La}^{3+}$ were low (i.e., the Sr/Cs molar ratios were 1.44 and 14.9 or the La/Cs molar ratios were 2.09 and 21.8), InSnS-1 possessed high $K_{\mathrm{d}}$ and $R$ (above $10^{3} \mathrm{~mL} / \mathrm{g}$ and $80 \%$ ) for $\mathrm{Cs}^{+}, \mathrm{Sr}^{2+}, \mathrm{La}^{3+}$ ions, respectively (Fig. $5 \mathrm{a}, \mathrm{d}$ ). The maximum values of $K_{\mathrm{d}} \mathrm{Cs}, K_{\mathrm{d}} \mathrm{Sr}, K_{\mathrm{d}} \mathrm{La}$ were $4.74 \times 10^{4} \mathrm{~mL} / \mathrm{g}, \quad 8.57 \times 10^{4} \mathrm{~mL} / \mathrm{g}, 4.89 \times 10^{5} \mathrm{~mL} / \mathrm{g}$, respectively, and the maximum removal rates of these ions were $97.93 \%$, $98.85 \%, 99.80 \%$, respectively. In $1 \mathrm{~mol} / \mathrm{L} \mathrm{HNO}_{3}$ solution, $K_{\mathrm{d}} \mathrm{Cs}$ are still above $10^{3} \mathrm{~mL} / \mathrm{g}$ with $R^{\mathrm{Cs}}$ around $80 \%$ even under very high concentrations of competing ions. By contrast, the removal 
performances of InSnS- 1 for $\mathrm{Sr}^{2+}$ or $\mathrm{La}^{3+}$ in $1 \mathrm{~mol} / \mathrm{L} \mathrm{HNO}_{3}$ were significantly lower, with $K_{\mathrm{d}} \mathrm{M}$ of $7.49-54.1 \mathrm{~mL} / \mathrm{g}$ and $R^{\mathrm{M}}$ of $0.74 \%-5.13 \%(\mathrm{M}=\mathrm{Sr}$ or La) (Fig. $5 \mathrm{~b}, \mathrm{e})$. Even in $3 \mathrm{~mol} / \mathrm{L}^{\mathrm{HNO}}$ solutions containing high concentrations of competing $\mathrm{Sr}^{2+}$ or $\mathrm{La}^{3+}$, InSnS- 1 still held $R^{\mathrm{Cs}}$ of $32.78 \%-47.74 \%$, while $R^{\mathrm{M}}(\mathrm{M}=\mathrm{Sr}$ or La) were only in the range of $0.42 \%-6.15 \%$ (Fig. $5 c, f$ ).

Obviously, the enhancement of acidity has resulted in a greater attenuation in the removal efficiencies of $\mathrm{Sr}^{2+}$ and $\mathrm{La}^{3+}$ rather

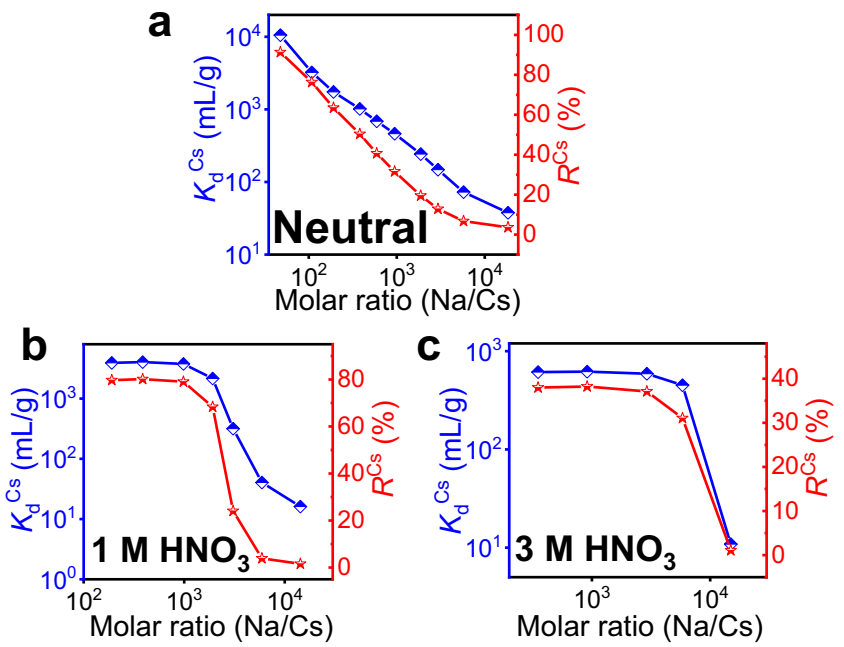

Fig. 4 Selective capture of $\mathrm{Cs}^{+}$by InSnS-1 in the coexistence of $\mathrm{Na}^{+}$and $\mathbf{C s}^{+} . K_{\mathrm{d}} \mathrm{Cs}$ and $R^{\mathrm{Cs}}$ values of $\mathrm{nnSnS}-1$ in a neutral, $\mathbf{b} 1 \mathrm{~mol} / \mathrm{L} \mathrm{HNO}_{3}$, and c $3 \mathrm{~mol} / \mathrm{L} \mathrm{HNO}_{3}$ solutions with different $\mathrm{Na} / \mathrm{Cs}$ molar ratios. Detailed experimental data can be found in Supplementary Table 15. than $\mathrm{Cs}^{+}$. In $1 \mathrm{~mol} / \mathrm{L}_{\mathrm{HNO}_{3}}$ solutions, $S F_{\mathrm{Cs} / \mathrm{Sr}}(183.45,630.87$, and 110.70) exceeded 100 at three different $\mathrm{Sr} / \mathrm{Cs}$ molar ratios, while $S F_{\mathrm{Cs} / \mathrm{La}}$ also reached 184.31 and 133.93 when $\mathrm{La} / \mathrm{Cs}$ molar ratios were 2.30 and 21.5, respectively. Even under $3 \mathrm{~mol} / \mathrm{L} \mathrm{HNO}_{3}$ condition, $S F_{\mathrm{Cs} / \mathrm{Sr}}$ remained 170.00 and 189.97 at the $\mathrm{Sr} / \mathrm{Cs}$ molar ratios of 1.48 and 14.8, respectively. The above results demonstrate that InSnS-1 can effectively achieve Cs-Sr (or CsLa) separation in acidic solutions even though the concentration of $\mathrm{Sr}^{2+}\left(\right.$ or $\left.\mathrm{La}^{3+}\right)$ is much higher than that of $\mathrm{Cs}^{+}$. Sulfide ion exchanger AgSnSe-1 can achieve Cs-Sr separation $\left(S F_{\mathrm{Cs} / \mathrm{Sr}}=\right.$ 121.4) in neutral solutions with low concentration of $\mathrm{Cs}^{+}$and $\mathrm{Sr}^{2+}$ (both around $\left.6 \mathrm{mg} / \mathrm{L}\right)^{51}$. However, to the best of our knowledge, no example of $S F_{\mathrm{C} / \mathrm{Sr}}$ (or $S F_{\mathrm{Cs} / \mathrm{La}}$ ) value that exceeds 100 in strongly acidic solution has been reported, where the $\mathrm{Sr}^{2+}$ (or $\mathrm{La}^{3+}$ ) ion concentration is much higher than the $\mathrm{Cs}^{+}$ion concentration. Clearly, the current InSnS-1 is the first case for the excellent Cs-Sr or Cs-La separation in an acidic environment, which demonstrates again its excellent selectivity for $\mathrm{Cs}^{+}$capture.

We also investigated the selective capture ability of InSnS-1 under the coexistence of $\mathrm{Sr}^{2+}, \mathrm{La}^{3+}$, and $\mathrm{Cs}^{+}$. In neutral solutions, their $K_{\mathrm{d}}\left(6.5 \times 10^{5} \mathrm{~mL} / \mathrm{g}, 5.3 \times 10^{4} \mathrm{~mL} / \mathrm{g}, 1.96 \times 10^{4} \mathrm{~mL} /\right.$ g, respectively) and $R$ values $(99.85 \%, 98.15 \%, 95.14 \%$, respectively) were all very high when the $\mathrm{Sr} / \mathrm{La} / \mathrm{Cs}$ molar ratio was 1.38:1.27:1 (Fig. 5g). Nevertheless, in $1 \mathrm{~mol} / \mathrm{L} \mathrm{HNO}_{3}$ solution, $K_{\mathrm{d}}{ }^{\mathrm{Cs}}$ could still reach $2.66 \times 10^{3} \mathrm{~mL} / \mathrm{g}$ with $R^{\mathrm{Cs}}$ of $72.71 \%$ when the $\mathrm{Sr} / \mathrm{La} / \mathrm{Cs}$ molar ratio was $13.6: 8.45: 1$, whereas $K_{\mathrm{d}} \mathrm{Sr}$ and $K_{\mathrm{d}} \mathrm{La}$ were only $4.37 \mathrm{~mL} / \mathrm{g}$ and $50.7 \mathrm{~mL} / \mathrm{g}$ with low $R^{\mathrm{Sr}}$ and $R^{\mathrm{La}}$ of $0.43 \%$ and $4.83 \%$, respectively (Fig. $5 \mathrm{~h}$ ). And when the $\mathrm{Sr} / \mathrm{La} / \mathrm{Cs}$ molar ratios were 1.47:0.925:1 and 13.6:8.45:1, $S F_{\mathrm{Cs} / \mathrm{Sr}}$ retained 249.89 and 610.01 , respectively. Even in the $3 \mathrm{~mol} / \mathrm{L} \mathrm{HNO}_{3}$ solution with high concentrations of $\mathrm{La}^{3+}$ and $\mathrm{Sr}^{2+}$ (the $\mathrm{Sr} / \mathrm{La} / \mathrm{Cs}$ molar ratio is 123:73.7:1), $R^{\mathrm{Cs}}$ could reach $19.1 \%$ which is significantly higher
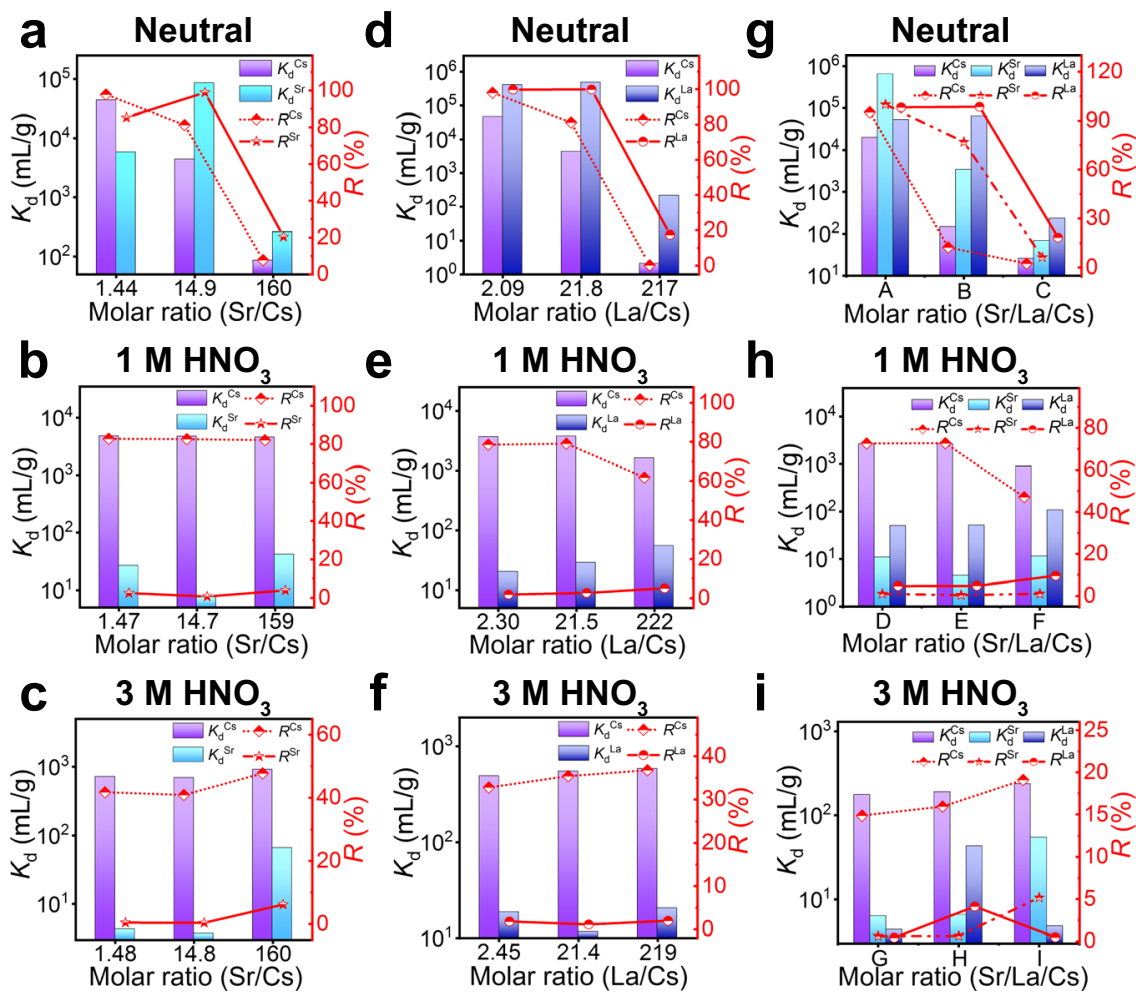

Fig. 5 Selective capture of $\mathbf{C s}^{+}$by InSnS-1 in the presence of $\mathbf{S r}^{2+}$ and/or $\mathbf{L a}^{\mathbf{3}+} . K_{\mathrm{d}}$ and $R$ of $\mathrm{Cs}^{+}$and $\mathrm{Sr}^{2+}$ ions removed by $\operatorname{lnSnS}-1$ in a neutral, $\mathbf{b} 1 \mathrm{~mol} / \mathrm{L}$ $\mathrm{HNO}_{3}$, and $\mathbf{c} 3 \mathrm{~mol} / \mathrm{L} \mathrm{HNO}_{3}$ solutions with different $\mathrm{Sr} / \mathrm{Cs}$ molar ratios. $K_{\mathrm{d}}$ and $R$ of $\mathrm{Cs}^{+}$and $\mathrm{La}^{3+}$ ions removed by $\mathrm{InSnS}-1$ in $\mathbf{d}$ neutral, e $1 \mathrm{~mol} / \mathrm{L} \mathrm{HNO}$, and $\mathbf{f} 3 \mathrm{~mol} / \mathrm{L} \mathrm{HNO}_{3}$ solutions with different $\mathrm{La} / \mathrm{Cs}$ molar ratios. $K_{\mathrm{d}}$ and $R$ of $\mathrm{Cs}^{+}, \mathrm{Sr}^{2+}$, and $\mathrm{La}^{3+}$ ions removed by $\operatorname{lnSnS}-1$ in $\mathbf{g}$ neutral, $\mathbf{h} 1 \mathrm{~mol} / \mathrm{L} \mathrm{HNO}{ }_{3}$, and i $3 \mathrm{~mol} / \mathrm{L} \mathrm{HNO}_{3}$ solutions with different $\mathrm{Sr} / \mathrm{La} / \mathrm{Cs}$ molar ratios $(\mathrm{A}=1.38: 1.27: 1, \mathrm{~B}=13.9: 8.58: 1, \mathrm{C}=123: 73.9: 1, \mathrm{D}=1.47: 0.925: 1, \mathrm{E}=13.6: 8.45: 1$,

$\mathrm{F}=122: 73.1: 1, \mathrm{G}=1.45: 0.880: 1, \mathrm{H}=13.5: 8.36: 1, \mathrm{I}=123: 73.7: 1)$. Detailed experimental data can be found in Supplementary Tables 16-18. 
than $R^{\mathrm{Sr}}$ and $R^{\mathrm{La}}(5.17 \%$ and $0.47 \%)$ (Fig. $\left.5 \mathrm{i}\right)$. The above results indicate that the selectivity of InSnS- 1 for $\mathrm{Cs}^{+}$is higher in acidic solution compared to in neutral solution.

Clearly, in neutral solutions with low ion concentrations InSnS-1 retains high removal efficiencies for all of $\mathrm{Cs}^{+}, \mathrm{Sr}^{2+}$, and $\mathrm{La}^{3+}$ in both individual competing ion system and mixed $\mathrm{Sr}^{2+}$, $\mathrm{La}^{3+}$, and $\mathrm{Cs}^{+}$system (Fig. 5a, d, g). However, in acidic solutions, $K_{\mathrm{d}}{ }^{\mathrm{Cs}}$ and $R^{\mathrm{Cs}}$ remain high and far exceed those of $\mathrm{La}^{3+}$ and $\mathrm{Sr}^{2+}$ ions even when the concentrations of $\mathrm{La}^{3+}$ and $\mathrm{Sr}^{2+}$ ions are much higher than that of $\mathrm{Cs}^{+}$. Besides, the increase in $\mathrm{Na}^{+}, \mathrm{Sr}^{2+}$ or $\mathrm{La}^{3+}$ concentration has less effect on Cs ${ }^{+}$capture by InSnS-1 in strongly acidic solutions ( 1 and $3 \mathrm{~mol} / \mathrm{L} \mathrm{HNO}_{3}$ solutions) than in neutral solutions. Similarly, we obtained similar results in $\mathrm{Cs}^{+}$ selectivity experiments with different $\mathrm{K} / \mathrm{Cs}$ or $\mathrm{Ca} / \mathrm{Cs}$ molar ratios (Supplementary Fig. 19, Supplementary Tables 19 and 20) as well as in actual water sample experiments (Supplementary Note 3). Such results demonstrate that the presence of $\mathrm{H}_{3} \mathrm{O}^{+}$is very favorable for enhancing the selective trapping ability of InSnS-1 for $\mathrm{Cs}^{+}$. This could also be attributed to the repulsive effect of $\mathrm{H}_{3} \mathrm{O}^{+}$on $\mathrm{Na}^{+}, \mathrm{Sr}^{2+}$, and $\mathrm{La}^{3+} . \mathrm{H}_{3} \mathrm{O}^{+}$has a small radius and is positively charged. $\mathrm{Sr}^{2+}$ and $\mathrm{La}^{3+}$ also have relatively small radii ${ }^{24}$ and highly positive charges compared to $\mathrm{Cs}^{+} . \mathrm{Na}^{+}$has a smaller radius than $\mathrm{Cs}^{+}$, although it has the same positive charge as $\mathrm{Cs}^{+}$. Therefore, $\mathrm{H}_{3} \mathrm{O}^{+}$has a relatively stronger repulsive effect on $\mathrm{Na}^{+}, \mathrm{Sr}^{2+}$, and $\mathrm{La}^{3+}$ which prevents them from entering the structure. Previous studies on the $\mathrm{Cs}^{+}$ion exchangers with high acid resistance mainly focused on the exchange capacity of materials. By contrast, this work provides the first systematic study of the effect of divalent and trivalent ions on the selective capture of $\mathrm{Cs}^{+}$under acidic conditions.

Desorption and cycling experiments. To investigate how well the material can be recycled, desorption and recycling experiments were conducted. The $0.2 \mathrm{~mol} / \mathrm{L} \mathrm{KCl}$ solution or $1 \mathrm{~mol} / \mathrm{L} \mathrm{HNO}_{3}$ solution can effectively desorb $\mathrm{Cs}^{+}$from InSnS-1-Cs (Supplementary Figs. 21 and 22). Due to the large adsorption capacity of InSnS-1 for Cs${ }^{+}$in $1 \mathrm{~mol} / \mathrm{L} \mathrm{HNO}_{3}$ solution, a small number of $\mathrm{Cs}^{+}$were retained in the sample, but this problem could be solved by replacing the fresh $\mathrm{HNO}_{3}$ solution several times. However, to ensure the accuracy of the eluent concentration in the cyclic experiments, the $\mathrm{HNO}_{3}$ solution was not renewed during the desorption process. The experimental results show that the $R^{\mathrm{Cs}}$ can be maintained after three cycles, and the desorption rates are all about $100 \%$ and the layered structure of the material was maintained (Supplementary Figs. 23 and 24). The experimental results show that although part of $\mathrm{Cs}^{+}$retaining in the structure affects the adsorption, the newly adsorbed $\mathrm{Cs}^{+}$can be completely desorbed in each cycle. The results also indirectly suggest that the acidified material (i.e., the material after desorption in nitric acid solution) still possesses the removal capacity for $\mathrm{Cs}^{+}$.

Column experiments. The breakthrough curves of $\mathrm{Cs}^{+}$in the ion-exchange columns filled with InSnS-1 have been carried out under neutral and acidic conditions to evaluate the potential of InSnS-1 for industrial applications. The color of the adsorbent (InSnS-1 crystals) was darkened after treatment under neutral condition while it was lightened under acidic condition (Fig. 6a). The breakthrough curves were fitted to the Thomas model ${ }^{52}$ (correlation coefficient $R^{2}>0.99$ ) with a maximum adsorption capacity of $216.06 \mathrm{mg} / \mathrm{g}$ under neutral condition and $50.50 \mathrm{mg} / \mathrm{g}$ (Supplementary Table 28) under acidic condition $(1 \mathrm{~mol} / \mathrm{L}$ $\mathrm{HNO}_{3}$ ). Usually, a value of $C_{\mathrm{t}} / C_{0}$ equal to 0.05 is used as a penetration point in industrial applications, taking into account the volume of wastewater treated ${ }^{53}$. For neutral and $1 \mathrm{~mol} / \mathrm{L}$ $\mathrm{HNO}_{3}$ solutions with high concentrations of $\mathrm{Cs}^{+}$(190.13 and
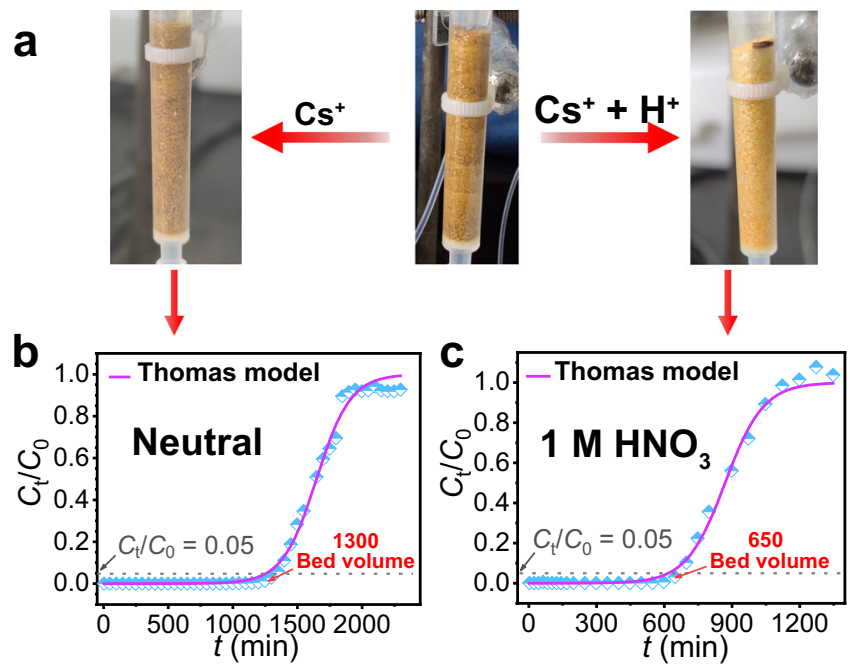

Fig. 6 Dynamic capture of $\mathrm{Cs}^{+}$by InSnS-1 as stationary phase in ionexchange columns. a Photographs of the ion-exchange columns loaded with InSnS-1 before and after the column experiments under the neutral and acidic conditions. The $\mathrm{Cs}^{+}$ion-exchange breakthrough curves of $\ln \mathrm{SnS}-1$ under $\mathbf{b}$ neutral $\left(C_{\mathrm{Cs}}=190.13 \mathrm{mg} / \mathrm{L}\right)$ and $\mathbf{c} 1 \mathrm{~mol} / \mathrm{L} \mathrm{HNO}_{3}$ conditions $\left(C_{C s}=84.25 \mathrm{mg} / \mathrm{L}\right)$. Purple curves are fitted by the Thomas model. Detailed experimental data can be found in Supplementary Tables 26-28.

$84.25 \mathrm{mg} / \mathrm{L}$, respectively), the treatment volumes to reach the breakthrough points are approximately 1300 and 650 bed volumes, respectively (Fig. 6b, c).

InSnS-1 exhibits high dynamic adsorption capacity and large effective treatment volume for neutral solution containing high concentration of $\mathrm{Cs}^{+}$. Such excellent treatment capacity exceeds that of most reported $\mathrm{Cs}^{+}$ion exchangers, e.g., MCC-g-AMP, M/ SZMs, PEI/ZnFC ${ }^{54-63}$. Notably, hitherto studies on the column separation of $\mathrm{Cs}^{+}$from strongly acidic solutions containing high concentration of $\mathrm{Cs}^{+}$are still rare ${ }^{16,64}$. The current ion-exchange column provides a practical example that shows the effective removal of $\mathrm{Cs}^{+}$from the highly acidic solution with high treatment amount. The above results demonstrate that InSnS-1 has great potential for practical application as a column packing in the field of radiocesium remediation.

\section{Discussion}

In this work, the rapid and highly selective separation of $\mathrm{Cs}^{+}$ions is achieved by the layered InSnS-1, especially for efficient capture of $\mathrm{Cs}^{+}$even under highly acidic conditions. InSnS- 1 as a $\mathrm{Cs}^{+}$ scavenger has the following main advantages: (i) excellent acid and irradiation resistances; (ii) fast adsorption kinetics and high adsorption capacities under neutral and acidic conditions; (iii) wide $\mathrm{pH}$ active range; (iv) effective separation of $\mathrm{Cs}^{+} / \mathrm{M}^{n+}$ $\left(\mathrm{M}^{n+}=\mathrm{Na}^{+}, \mathrm{Sr}^{2+}\right.$, and $\left.\mathrm{La}^{3+}\right)$ in acidic solutions; (v) easy desorption and reuse; (vi) effective dynamic separation of $\mathrm{Cs}^{+}$as stationary phase in ion-exchange columns. The uptake mechanism of $\mathrm{Cs}^{+}$and $\mathrm{H}_{3} \mathrm{O}^{+}$is directly visualized through single-crystal structural analyses. All promising features of InSnS-1 for the $\mathrm{Cs}^{+}$ capture originate from the extremely strong interactions between soft $\mathrm{S}^{2-}$ of sulfide layers and relatively soft $\mathrm{Cs}^{+}$, the adjustable interlayer spacing, and structural flexibility of InSnS-1 even in acidic condition. In addition, our study elucidates the nonnegligible facilitating role of $\mathrm{H}_{3} \mathrm{O}^{+}$in the selective capture of $\mathrm{Cs}^{+}$ under acidic conditions. The important influence of the shortest $\mathrm{K}-\mathrm{S}$ distance of $\mathrm{K}^{+}$-directed metal sulfides on the ion-exchange performance is also revealed. This work highlights metal sulfides for the selective capture of $\mathrm{Cs}^{+}$ion from strongly acidic nuclear wastewaters and sheds light on the design of novel acid-tolerant 
sulfide-based ion-exchange materials for radiocesium decontamination with practical applications.

\section{Methods \\ Starting materials. $\mathrm{K}_{2} \mathrm{CO}_{3}$ (AR, General-Reagent), S (CP, Kermel), Sn (99\%, damas-beta), In (99.99\%, CNBM (Cheng Du) Optoelectronic Materials Co., LTD), $\mathrm{CsCl}$ (99.99\%, Shanghai Longjin Metal Materials Co., Ltd.), $\mathrm{SrCl}_{2} \cdot 6 \mathrm{H}_{2} \mathrm{O}$ (AR, Tianjin Guangfu Reagent Co., Ltd.), $\mathrm{LaCl}_{3} \cdot 7 \mathrm{H}_{2} \mathrm{O}$ (AR, Tianjin Guangfu Reagent Co., Ltd.), $\mathrm{NaCl}$ (AR, Sinopharm Chemical Reagent Co., Ltd), $\mathrm{CaCl}_{2} \cdot 2 \mathrm{H}_{2} \mathrm{O}(74 \%$, Shanghai Sili Chemical Plant), $\mathrm{MgCl}_{2}$ (AR, Adamas Reagent Co., Ltd). All the chemicals were used without further purification.}

Synthesis of InSnS-1. $\mathrm{KInS}_{2}$ precursor was firstly synthesized by hydrothermal method. A mixture of $\mathrm{K}_{2} \mathrm{CO}_{3}(9.0 \mathrm{mmol}, 1.2439 \mathrm{~g})$, In $(9.0 \mathrm{mmol}, 1.0334 \mathrm{~g})$, $\mathrm{S}$ $(30.0 \mathrm{mmol}, 0.9618 \mathrm{~g})$, and $\mathrm{H}_{2} \mathrm{O}(1.5 \mathrm{~mL})$ was heated in a $28 \mathrm{~mL}$ polytetrafluoroethylene (PTFE) lined stainless steel autoclave at $220^{\circ} \mathrm{C}$ for 2 days to obtain microcrystalline powder of $\mathrm{KInS}_{2}$. Then a mixture of $\mathrm{KInS}_{2}(3.0 \mathrm{mmol}$, $0.6541 \mathrm{~g})$, Sn $(3.0 \mathrm{mmol}, 0.3561 \mathrm{~g}), \mathrm{S}(6.0 \mathrm{mmol}, 0.1924 \mathrm{~g})$ was sealed under vacuum in a quartz tube. Then the quartz tube was heated to $750^{\circ} \mathrm{C}$ in $4 \mathrm{~h}$ and maintained at $750^{\circ} \mathrm{C}$ for 4 days, followed by program-controlled cooling to $550^{\circ} \mathrm{C}$ for 3 days before turning off the furnace. After that, the quartz tube was naturally cooled to room temperature in the furnace. The crystals products were washed with deionized water and ethanol, and dried in natural condition. $1.2261 \mathrm{~g}$ of pure yellow flaky crystals of InSnS-1 could be obtained, which are stable in water and air. The higher actual yield than the theoretical value $(1.2026 \mathrm{~g})$ may be attributed to the water absorption of the compound.

Syntheses of three ion-exchange crystal products. $100 \mathrm{mg}$ of InSnS- 1 crystals were mixed with $100 \mathrm{~mL}$ neutral solution of $5000 \mathrm{mg} / \mathrm{L} \mathrm{Cs}^{+}$ions, $100 \mathrm{~mL} 1 \mathrm{~mol} / \mathrm{L}$ nitric acid solution of $500 \mathrm{mg} / \mathrm{L} \mathrm{Cs}{ }^{+}$ions, and $100 \mathrm{~mL} 1 \mathrm{~mol} / \mathrm{L} \mathrm{HNO}_{3}$ solution, respectively, which were shaken for $24 \mathrm{~h}$ at room temperature (RT). Then the crystals were washed with deionized water and ethanol, and dried naturally to afford the ion-exchange products formulated as $\mathrm{CsInSnS}_{4}$ (denoted as InSnS-1-Cs), $\mathrm{Cs}_{1 / 3}\left(\mathrm{H}_{3} \mathrm{O}\right)_{2 / 3} \mathrm{InSnS}_{4}$ (denoted as InSnS-1-Cs/H), and $\left(\mathrm{H}_{3} \mathrm{O}\right) \mathrm{InSnS}_{4} \cdot \mathrm{H}_{2} \mathrm{O}$ (denoted as InSnS-1-H), respectively.

Characterizations. Single-crystal diffraction data for InSnS-1, InSnS-1-Cs, InSnS$1-\mathrm{Cs} / \mathrm{H}$, and InSnS-1-H were collected with SuperNova CCD diffractometer with graphite monochromated $\operatorname{MoK} \alpha(\lambda=0.71073 \AA)$. Powder X-ray diffraction (PXRD) patterns were obtained at RT by using a Miniflex II diffractometer with $\mathrm{CuK \alpha}(\lambda=1.54178 \AA)$ at $30 \mathrm{kV}$ and $15 \mathrm{~mA}$ in the angular range of $2 \theta=5-65^{\circ}$. Energy dispersive spectroscopy (EDS), scanning electron microscope (SEM), and elemental distribution mapping analysis were carried out through a JEOL JSM$6700 \mathrm{~F}$ scanning electron microscope. X-ray photoelectron spectroscopy (XPS) analysis was carried out through a ESCALAB 250Xi spectrometer with $\mathrm{AlKa}$ radiation. UV/visible spectra were obtained with a PerkinElmer Lambda 900 at RT. Thermo Gravimetric Analysis (TGA) was performed on a NETZSCH STA 449F3 DTA-TG analyzer. Ion concentrations in solutions were measured by inductively coupled plasma-mass spectroscopy (ICP-MS) or inductively coupled plasmaoptical emission spectroscopy (ICP-OES). ICP-MS and ICP-OES tests were carried out by XSerise II and Thermo 7400, respectively. InSnS-1 crystal samples were irradiated with $\gamma$-rays at a total dose of $100 \mathrm{kGy}(1.1 \mathrm{kGy} / \mathrm{h}$ for $95 \mathrm{~h})$ and $200 \mathrm{kGy}$ $\left(1.1 \mathrm{kGy} / \mathrm{h}\right.$ for $181.8 \mathrm{~h}$ ) using a ${ }^{60} \mathrm{Co}$ irradiation source ( 2 million curies) provided by Detection Center of Suzhou CNNC Huadong Radiation Co., Ltd, China.

Acid stability experiments. In acid stability experiments, InSnS- 1 crystals were immersed in different concentrations of $\mathrm{HNO}_{3}$ solutions for $10 \mathrm{~h}$. After solid-liquid separation, the concentrations of leaching $\mathrm{Sn}$ and In in the solutions were determined by ICP-MS and the leaching percentages of Sn and In from the sample were inferred. PXRD of solid materials were measured to confirm whether the material framework remained stable. The equations and detailed descriptions used for data analysis can be found in Supplementary Note 2.

Batch ion-exchange experiments. A typical ion-exchange experiment of InSnS-1 was carried out in a $20 \mathrm{~mL}$ glass bottle containing an aqueous solution $(\mathrm{V} / \mathrm{m}=1000 \mathrm{~mL} / \mathrm{g}$ ) of $\mathrm{CsCl}$ and InSnS-1 powder (obtained by grinding InSnS-1 crystals). The mixture was shaken in a shaker for $4 \mathrm{~h}$ at RT and then centrifuged for separation. The supernatant was filtered and diluted for ICP testing and the solid was washed several times with deionized water and anhydrous ethanol before drying. The equations and detailed descriptions used for data analysis can be found in Supplementary Note 2.

In isotherm experiments, different concentrations of $\mathrm{Cs}^{+}$solutions under neutral or strongly acidic condition $\left(1 \mathrm{~mol} / \mathrm{L} \mathrm{HNO}_{3}\right)$ were prepared $(44-1904 \mathrm{mg} / \mathrm{L}$ $\mathrm{Cs}^{+}$at $\mathrm{pH} \sim 7 ; 4-590 \mathrm{mg} / \mathrm{L} \mathrm{Cs}{ }^{+}$in $1 \mathrm{~mol} / \mathrm{L} \mathrm{HNO}_{3}$ ). In kinetics experiments, $50 \mathrm{mg}$ of ground InSnS-1 crystal powder was added to $50 \mathrm{~mL}$ of $3.44 \mathrm{mg} / \mathrm{L} \mathrm{Cs}{ }^{+}$solution or $50 \mathrm{~mL}$ of $1 \mathrm{~mol} / \mathrm{L} \mathrm{HNO}_{3}$ solution with $4.3 \mathrm{mg} / \mathrm{L} \mathrm{Cs}{ }^{+}$under magnetic stirring at RT. The suspensions were sampled at different time intervals and then filtered to test the $\mathrm{Cs}^{+}$concentrations in the solutions. In $\mathrm{pH}$-dependent experiments, solutions with initial $\mathrm{Cs}^{+}$concentrations of $4.6-4.88 \mathrm{mg} / \mathrm{L}$ at different acidity and alkalinity $\left(\mathrm{pH}=0.02-12.04,2 \mathrm{~mol} / \mathrm{L} \mathrm{HNO}_{3}, 3 \mathrm{~mol} / \mathrm{L} \mathrm{HNO}_{3}\right)$ were prepared. In the competitive ion-exchange experiments, $\mathrm{Na}^{+} / \mathrm{Cs}^{+}, \mathrm{Sr}^{2+} / \mathrm{Cs}^{+}, \mathrm{La}^{3+} / \mathrm{Cs}^{+}, \mathrm{La}^{3+} / \mathrm{Sr}^{2+} /$ $\mathrm{Cs}^{+}, \mathrm{Na}^{+} / \mathrm{Ca}^{2+} / \mathrm{Mg}^{2+} / \mathrm{Sr}^{2+} / \mathrm{Cs}^{+}$solutions at different acidities were prepared. The acidity or alkalinity of all solutions was adjusted by $\mathrm{HNO}_{3}$ and $\mathrm{NaOH}$ solutions. In actual water samples, $\mathrm{Cs}^{+}$ions were added to river water (Fuzhou, Fujian and Longyan, Fujian) and seawater (Gulangyu, Xiamen, Fujian) to simulate $\mathrm{Cs}^{+}$ contaminated water bodies.

In the desorption experiments, the complete $\mathrm{Cs}^{+}$-exchanged samples (InSnS-1Cs) were desorbed with $0.2 \mathrm{~mol} / \mathrm{L} \mathrm{KCl}$ solution or $1 \mathrm{~mol} / \mathrm{L} \mathrm{HNO}_{3}$ solution $(V / m=1000 \mathrm{~mL} / \mathrm{g}$, shaking for $12 \mathrm{~h}$ at RT). In the cycle experiments, $88.4 \mathrm{mg} / \mathrm{L}$ $\mathrm{Cs}^{+}$solution was used for the adsorption and $1 \mathrm{~mol} / \mathrm{L} \mathrm{HNO}_{3}$ solution was used as the eluant. Overall, 3 cycles of adsorption-desorption were performed. The specific experimental procedures are shown in Supplementary Fig. 1 and detailed descriptions are given in Supplementary Note 1.

Column experiments. The experimental setups are shown in Supplementary Fig. 2. $1.45 \mathrm{~g}$ of InSnS-1 crystal samples were packed into a $1 \mathrm{~mL}$ polyethylene column with an inner diameter of $0.56 \mathrm{~cm}$ and a packing height of $\sim 4 \mathrm{~cm}$. A sieve plate with the $50 \mu \mathrm{m}$ pore size was put at the bottom of the column to avoid the loss of solid samples. Neutral solution with a concentration of $190.13 \mathrm{mg} / \mathrm{L} \mathrm{Cs}^{+}$ and $1 \mathrm{~mol} / \mathrm{L} \mathrm{HNO}_{3}$ solution with $84.25 \mathrm{mg} / \mathrm{L} \mathrm{Cs}^{+}$passed through the ion-exchange column at a flow rate of $1 \mathrm{~mL} / \mathrm{min}$, respectively. The effluent solution sample within each $5 \mathrm{~min}$ was collected in a glass test tube and the measured concentration was approximated as the concentration at the intermediate moment. The solution flow rate and sample collection were controlled by the combined use of a peristaltic pump and an automatic collector.

\section{Data availability}

The single-crystal structures of InSnS-1, InSnS-1-Cs, InSnS-1-Cs/H, and InSnS-1-H are archived at the Cambridge Crystallographic Data Centre under the reference number CCDC-2107570, CCDC-2107571, CCDC-2107573, CCDC-2107572, respectively. These data can be obtained free of charge from The Cambridge Crystallographic Data Centre via www.ccdc.cam.ac.uk/data_request/cif. Any further relevant data are available from the authors upon reasonable request. The ion-exchange data generated in this study are provided in the Supplementary Information/Source Data file. Source data are provided with this paper.

Received: 14 September 2021; Accepted: 11 January 2022;

Published online: 03 February 2022

\section{References}

1. Nash, K. L. \& Braley, J. C. in Advanced Separation Techniques for Nuclear Fuel Reprocessing and Radioactive Waste Treatment 3-22 (2011).

2. Figueiredo, B. R., Cardoso, S. P., Portugal, I., Rocha, J. \& Silva, C. M. Inorganic ion exchangers for cesium removal from radioactive wastewater. Sep. Purif. Rev. 47, 306-336 (2017)

3. Chen, $\mathrm{S}$. et al. A review on emerging composite materials for cesium adsorption and environmental remediation on the latest decade. Sep. Purif. Technol. 251, 117340 (2020)

4. Matsuda, K., Yamamoto, S. \& Miyamoto, K. Comparison of ${ }^{137}$ Cs uptake, depuration and continuous uptake, originating from feed, in five salmonid fish species. J. Environ. Radioact. 222, 106350 (2020).

5. Lang, A. R. et al. Cesium and strontium contamination of nuclear plant stainless steel: implications for decommissioning and waste minimization. ACS Omega 4, 14420-14429 (2019).

6. Wang, J. C., Jing, S. \& Chen, J. Demonstration of a crown ether process for partitioning strontium from high level liquid waste (HLLW). Radiochim. Acta 104, 107-115 (2016).

7. Duan, W. et al. Demonstration of an improved total partitioning process for high level liquid waste using annular centrifugal contactors. Sep. Sci. Technol. 50, 1249-1256 (2015).

8. Xiao, C. et al. Highly efficient separation of trivalent minor actinides by a layered metal sulfide $\left(\mathrm{KInSn}_{2} \mathrm{~S}_{6}\right)$ from acidic radioactive waste. J. Am. Chem. Soc. 139, 16494-16497 (2017).

9. Wang, J. L. \& Zhuang, S. T. Removal of cesium ions from aqueous solutions using various separation technologies. Rev. Environ. Sci. Bio-Technol. 18 231-269 (2019)

10. Rahman, R. O. A., Ibrahium, H. A. \& Hung, Y. T. Liquid radioactive wastes treatment: a review. Water 3, 551-565 (2011).

11. Manos, M. J. \& Kanatzidis, M. G. Metal sulfide ion exchangers: superior sorbents for the capture of toxic and nuclear waste-related metal ions. Chem. Sci. 7, 4804-4824 (2016).

12. Tang, J. H., Sun, H. Y., Ma, W., Feng, M. L. \& Huang, X. Y. Recent progress in developing crystalline ion exchange materials for the removal of radioactive ions. Chinese. J. Struct. Chem. 39, 2157-2171 (2020). 
13. Deng, H. et al. An efficient composite ion exchanger of silica matrix impregnated with ammonium molybdophosphate for cesium uptake from aqueous solution. Chem. Eng. J. 286, 25-35 (2016).

14. Holdsworth, A. E. et al. The effect of gamma irradiation on the ion exchange properties of caesium-selective ammonium phosphomolybdatepolyacrylonitrile (AMP-PAN) composites under spent fuel recycling conditions. Separations 6, 23 (2019).

15. Tao, Q., Wang, X., Huang, D., Prabaharan, K. \& Dai, Y. Adsorption of cesium from aqueous solution of highly concentrated nitric acid using supermolecule/ ordered mesoporous carbon composite. Water Air Soil Pollut. 229, 361 (2018).

16. Wu, Y., Zhang, X. X., Kim, S. Y. \& Wei, Y. Z. Simultaneous separation and recovery of $\mathrm{Cs}(\mathrm{I})$ and $\mathrm{Sr}(\mathrm{II})$ using a hybrid macrocyclic compounds loaded adsorbent. kinetic, equilibrium and dynamic adsorption studies. J. Nucl. Sci. Technol. 53, 1968-1977 (2016).

17. Manos, M. J. \& Kanatzidis, M. G. Highly efficient and rapid $\mathrm{Cs}^{+}$uptake by the layered metal sulfide $\mathrm{K}_{2 x} \mathrm{Mn}_{x} \mathrm{Sn}_{3-x} \mathrm{~S}_{6}$ (KMS-1). J. Am. Chem. Soc. 131, 6599-6607 (2009).

18. Mertz, J. L., Fard, Z. H., Malliakas, C. D., Manos, M. J. \& Kanatzidis, M. G. Selective removal of $\mathrm{Cs}^{+}, \mathrm{Sr}^{2+}$, and $\mathrm{Ni}^{2+}$ by $\mathrm{K}_{2 x} \mathrm{Mg}_{x} \mathrm{Sn}_{3-x} \mathrm{~S}_{6}(x=0.5 \sim 1)$ (KMS-2) relevant to nuclear waste remediation. Chem. Mater. 25, 2116-2127 (2013).

19. Sarma, D., Malliakas, C. D., Subrahmanyam, K. S., Islama, S. M. \& Kanatzidis, M. G. $\mathrm{K}_{2 x} \mathrm{Sn}_{4-x} \mathrm{~S}_{8-x}(x=0.65 \sim 1)$ : a new metal sulfide for rapid and selective removal of $\mathrm{Cs}^{+}, \mathrm{Sr}^{2+}$ and $\mathrm{UO}_{2}^{2+}$ ions. Chem. Sci. 7, 1121-1132 (2016).

20. Olatunji, M. A., Khandaker, M. U., Mahmud, H. N. M. E. \& Amin, Y. M. Influence of adsorption parameters on cesium uptake from aqueous solutions -a brief review. RSC Adv. 5, 71658-71683 (2015).

21. Manos, M. J., Petkov, V. G. \& Kanatzidis, M. G. $\mathrm{H}_{2 x} \mathrm{Mn}_{x} \mathrm{Sn}_{3-x} \mathrm{~S}_{6}$ $(x=0.11 \sim 0.25)$ : a novel reusable sorbent for highly specific mercury capture under extreme pH conditions. Adv. Funct. Mater. 19, 1087-1092 (2009).

22. Manos, M. J., Ding, N. \& Kanatzidis, M. G. Layered metal sulfides: exceptionally selective agents for radioactive strontium removal. Proc. Natl. Acad. Sci. USA 105, 3696-3699 (2008).

23. Yohannan, J. P. \& Vidyasagar, K. Syntheses, structural variants and characterization of $\mathrm{AIn} M^{\prime} \mathrm{S}_{4}\left(\mathrm{~A}=\right.$ alkali metals, $\left.\mathrm{Tl} ; M^{\prime}=\mathrm{Ge}, \mathrm{Sn}\right)$ compounds; facile ion-exchange reactions of layered $\mathrm{NaInSnS}_{4}$ and $\mathrm{KInSnS}_{4}$ compounds. J. Solid State Chem. 238, 291-302 (2016).

24. Marcus, Y. A simple empirical-model describing the thermodynamics of hydration of ions of widely varying charges, sizes, and shapes. Biophys. Chem. 51, 111-127 (1994).

25. Pearson, R. G. Hard and soft acids and bases. J. Am. Chem. Soc. 85, 3533-3539 (1963).

26. Ding, N. \& Kanatzidis, M. G. Selective incarceration of caesium ions by venus flytrap action of a flexible framework sulfide. Nat. Chem. 2, 187-191 (2010).

27. Feng, M. L., Kong, D. N., Xie, Z. L. \& Huang, X. Y. Three-dimensional chiral microporous germanium antimony sulfide with ion-exchange properties. Angew. Chem., Int. Ed. 47, 8623-8626 (2008).

28. Gao, Y. J. et al. An easily synthesized microporous framework material for the selective capture of radioactive $\mathrm{Cs}^{+}$and $\mathrm{Sr}^{2+}$ ions. J. Mater. Chem. A 6, 3967-3976 (2018).

29. Wang, Y. et al. Umbellate distortions of the uranyl coordination environment result in a stable and porous polycatenated framework that can effectively remove cesium from aqueous solutions. J. Am. Chem. Soc. 137, 6144-6147 (2015).

30. Zhang, R. C. et al. Copper-rich framework sulfides: $\mathrm{A}_{4} \mathrm{Cu}_{8} \mathrm{Ge}_{3} \mathrm{~S}_{12}(\mathrm{~A}=\mathrm{K}, \mathrm{Rb})$ with cubic perovskite structure. Inorg. Chem. 49, 6372-6374 (2010)

31. Wang, R. et al. Synthesis, crystal structure, electronic structure, and photoelectric response properties of $\mathrm{KCu}_{2} \mathrm{SbS}_{3}$. Dalton Trans. 45, 3473-3479 (2016).

32. Fabry, J. et al. Structure determination of $\mathrm{KLaS}_{2}, \mathrm{KPrS}_{2}, \mathrm{KEuS}_{2}, \mathrm{KGdS}_{2}, \mathrm{KLuS}_{2}$, $\mathrm{KYS}_{2}, \mathrm{RbYS}_{2}, \mathrm{NaLaS}_{2}$ and crystal-chemical analysis of the group 1 and thallium(I) rare-earth sulfide series. Acta Crystallogr. Sect. B-Struct. Sci.Cryst. Eng. Mat. 70, 360-371 (2014).

33. Pogu, A., Jaschin, P. W., Varma, K. B. R. \& Vidyasagar, K. Syntheses, structural variants and characterization of $\mathrm{A}_{2} \mathrm{CdSn}_{2} \mathrm{~S}_{6}(\mathrm{~A}=\mathrm{Cs}, \mathrm{Rb}$ and $\mathrm{K})$ compounds. J. Solid State Chem. 277, 713-720 (2019).

34. $\mathrm{Li}, \mathrm{X}$. et al. Syntheses, crystal structures and physical properties of three new chalcogenides: $\mathrm{NaGaGe}_{3} \mathrm{Se}_{8}, \mathrm{~K}_{3} \mathrm{Ga}_{3} \mathrm{Ge}_{7} \mathrm{~S}_{20}$, and $\mathrm{K}_{3} \mathrm{Ga}_{3} \mathrm{Ge}_{7} \mathrm{Se}_{20}$. Dalton Trans. 45, 532-538 (2016).

35. Manos, M. J., Chrissafis, K. \& Kanatzidis, M. G. Unique pore selectivity for Cs + and exceptionally high $\mathrm{NH}_{4}{ }^{+}$exchange capacity of the chalcogenide material $\mathrm{K}_{6} \mathrm{Sn}\left[\mathrm{Zn}_{4} \mathrm{Sn}_{4} \mathrm{~S}_{17}\right]$. J. Am. Chem. Soc. 128, 8875-8883 (2006).

36. Chastain, J. \& Moulder, J. F. Handbook of X-ray Photoelectron Spectroscopy: A Reference Book of Standard Spectra for Identification and Interpretation of XPS Data (Physical Electronics,1995).

37. Ho, Y. S., Wase, D. A. J. \& Forster, C. F. Kinetic studies of competitive heavy metal adsorption by sphagnum moss peat. Environ. Technol. 17, 71-77 (1996).
38. Ho, Y. S. Review of second-order models for adsorption systems. J. Hazard. Mater. 136, 681-689 (2006).

39. Duong, D. D. Adsorption Analysis: Equilibria and Kinetics (1998).

40. Bayulken, S., Bascetin, E., Guclu, K. \& Apak, R. Investigation and modeling of cesium(I) adsorption by Turkish clays: bentonite, zeolite, sepiolite, and kaolinite. Environ. Prog. Sustain. Energy 30, 70-80 (2011).

41. Chen, G. R. et al. Prussian blue (PB) granules for cesium (Cs) removal from drinking water. Sep. Purif. Technol. 143, 146-151 (2015).

42. Tan, L., Wang, S., Du, W. \& Hu, T. Effect of water chemistries on adsorption of Cs(I) onto graphene oxide investigated by batch and modeling techniques. Chem. Eng. J. 292, 92-97 (2016).

43. Park, Y., Lee, Y. C., Shin, W. S. \& Choi, S. J. Removal of cobalt, strontium and cesium from radioactive laundry wastewater by ammonium molybdophosphate-polyacrylonitrile (AMP-PAN). Chem. Eng. J. 162, 685-695 (2010).

44. Liu, X. et al. Orderly porous covalent organic frameworks-based materials: Superior adsorbents for pollutants removal from aqueous solutions. The Innovation 2, 100076 (2021).

45. Wang, S. et al. Highly efficient adsorption and immobilization of U(VI) from aqueous solution by alkalized MXene-supported nanoscale zero-valent iron. J. Hazard. Mater. 408, 124949 (2021).

46. Qi, X. H. et al. A two-dimensionally microporous thiostannate with superior $\mathrm{Cs}^{+}$and $\mathrm{Sr}^{2+}$ ion-exchange property. J. Mater. Chem. A 3, 5665-5673 (2015).

47. Feng, M. L. et al. Efficient removal of $\left[\mathrm{UO}_{2}\right]^{2+}, \mathrm{Cs}^{+}$, and $\mathrm{Sr}^{2+}$ ions by radiation-resistant gallium thioantimonates. J. Am. Chem. Soc. 140, 11133-11140 (2018)

48. Wang, K. Y. et al. Di-lacunary $\left[\operatorname{In}_{6} \mathrm{~S}_{15}\right]^{12-}$ cluster: the building block of a highly negatively charged framework for superior $\mathrm{Sr}^{2+}$ adsorption capacities. Chem. Commun. 56, 3409-3412 (2020).

49. Sun, M. et al. Removal of $\mathrm{Sr}^{2+}$ ions by a high-capacity indium sulfide exchanger containing permeable layers with large pores. Inorg. Chem. 59, 13822-13826 (2020).

50. Zhang, B. et al. Fast and selective removal of aqueous uranium by a K

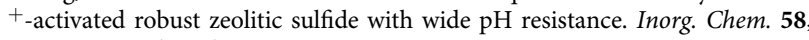
11622-11629 (2019)

51. Ding, D. et al. Efficient $\mathrm{Cs}^{+}-\mathrm{Sr}^{2+}$ separation over a microporous silver selenidostannate synthesized in deep eutectic solvent. Inorg. Chem. 59, 9638-9647 (2020).

52. Mathialagan, T. \& Viraraghavan, T. Adsorption of cadmium from aqueous solutions by perlite. J. Hazard. Mater. 94, 291-303 (2002).

53. Chen, Z., Wu, Y., Wei, Y. \& Mimura, H. Preparation of slica-based titanate adsorbents and application for strontium removal from radioactive contaminated wastewater. J. Radioanal. Nucl. Chem. 307, 931-940 (2016).

54. Dong, Z., Du, J., Chen, Y., Zhang, M. \& Zhao, L. A comparative study of immobilizing ammonium molybdophosphate onto cellulose microsphere by radiation post-grafting and hybrid grafting for cesium removal. Environ. Pollut. 273, 116432 (2021).

55. Lei, H. et al. Facile fabrication of metakaolin/slag-based zeolite microspheres (M/SZMs) geopolymer for the efficient remediation of $\mathrm{Cs}^{+}$and $\mathrm{Sr}^{2+}$ from aqueous media. J. Hazard. Mater. 406, 124292 (2021).

56. Malakhova, I. et al. Composite $\mathrm{Zn}$ (II) ferrocyanide/polyethylenimine cryogels for point-of-use selective removal of Cs-137 radionuclides. Molecules 26, 4604 (2021).

57. Chen, X. et al. High-efficiency continuous enrichment of cesium ions using CuFC composite microspheres: dynamic adsorption and mechanism analysis. J. Radioanal. Nucl. Chem. 326, 959-973 (2020).

58. Abou-Lilah, R. A. et al. Efficiency of bentonite in removing cesium, strontium, cobalt and uranium ions from aqueous solution: Encapsulation with alginate for column application. Int. J. Environ. Anal. Chem. https://doi.org/10.1080/ 03067319.2020.1761348 (2020).

59. El-Bahy, S. M., Fadel, D. A., El-Bahy, Z. M. \& Metwally, A. M. Rapid and highly efficient cesium removal by newly synthesized carbomer encapsulated potassium copper hexacyanoferrate composite. J. Environ. Chem. Eng. 6, 1875-1885 (2018)

60. Du, Z., Jia, M. \& Wang, X. Cesium removal from solution using PAN-based potassium nickel hexacyanoferrate (II) composite spheres. J. Radioanal. Nucl. Chem. 298, 167-177 (2013).

61. Chang, S. et al. Batch and fixed-bed column studies for selective removal of cesium ions by compressible Prussian blue/polyurethane sponge. RSC Adv. 8, 36459-36467 (2018).

62. Zhu, Y., Zhang, H., Hui, A., Ye, X. \& Wang, A. Fabrication of porous adsorbent via eco-friendly pickering-MIPEs polymerization for rapid removal of $\mathrm{Rb}^{+}$and $\mathrm{Cs}^{+}$. J. Environ. Chem. Eng. 6, 849-857 (2018).

63. Nilchi, A., Saberi, R., Sepanloo, K., Mehraban, O. \& Ahangari, R. Evaluation of $\left[\mathrm{Zn}(\mathrm{bim})_{2}(\mathrm{bdc})\right]_{n}$-MOF for adsorption of $\mathrm{Cs}^{+}$ions from aqueous solution using batch and fixed bed operations. Desalin. Water Treat. 201, 301-312 (2020). 
64. Park, J. I., Kim, J. S., Kim, Y. B., Kwon, H. J. \& Park, Y. J. Evaluation of polyethersulfone-based composite for selective separation of cesium from acidic media. Bull. Korean Chem. Soc. 37, 802-809 (2016).

\section{Acknowledgements}

We thank financial support from the National Natural Science Foundation of China (Nos. 22076185 and 21771183, M.F.), the Natural Science Foundation of Fujian Province (No. 2018J01027, M.F.), and FJIRSM\&IUE Joint Research Fund (No. RHZX-2018-005, M.F.). We also thank Qin Wei for the provision of distilled water.

\section{Author contributions}

The manuscript was written through contributions of all authors. J.T., M.F., and X.H. conceived the project. J.T. designed and performed most of the experiments and analyzed the data. J.J. offered help in data analyses. W.L., X.Z., W.M., J.L., Y.P., and T.L. offered help in the partial experiments. J.T. prepared the manuscript. M.F. and X.H. revised the manuscript. M.F. supervised the project.

\section{Competing interests}

The authors declare no competing interests.

\section{Additional information}

Supplementary information The online version contains supplementary material available at https://doi.org/10.1038/s41467-022-28217-8.
Correspondence and requests for materials should be addressed to Mei-Ling Feng

Peer review information Nature Communications thanks Manolis Manos and the other, anonymous, reviewer(s) for their contribution to the peer review of this work.

Reprints and permission information is available at http://www.nature.com/reprints

Publisher's note Springer Nature remains neutral with regard to jurisdictional claims in published maps and institutional affiliations.

cc (i) Open Access This article is licensed under a Creative Commons Attribution 4.0 International License, which permits use, sharing, adaptation, distribution and reproduction in any medium or format, as long as you give appropriate credit to the original author(s) and the source, provide a link to the Creative Commons license, and indicate if changes were made. The images or other third party material in this article are included in the article's Creative Commons license, unless indicated otherwise in a credit line to the material. If material is not included in the article's Creative Commons license and your intended use is not permitted by statutory regulation or exceeds the permitted use, you will need to obtain permission directly from the copyright holder. To view a copy of this license, visit http://creativecommons.org/ licenses/by/4.0/.

(C) The Author(s) 2022 